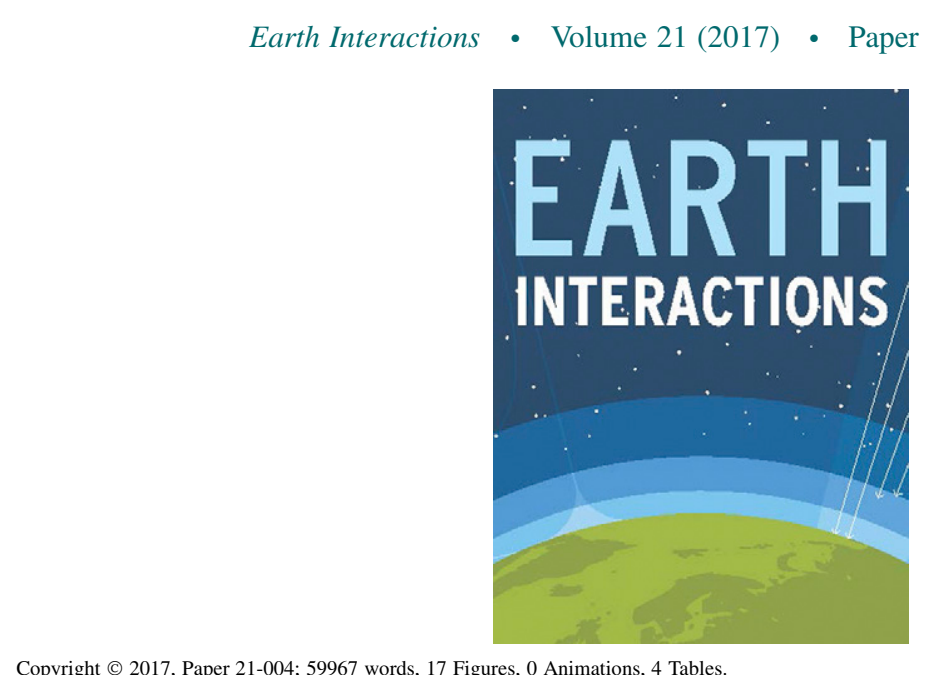

Copyright $\odot$ 2017, Paper 21-004; 59967 words, 17 Figures, 0 Animations, 4 Tables.

http://EarthInteractions.org

\title{
Assessment of a Long-Term High- Resolution Hydroclimatic Dataset for the U.S. Midwest ${ }^{\oplus}$
}

\section{Dev Niyogi, ${ }^{\text {a,b,c }}$ Elin M. Jacobs, ${ }^{\text {d,e }}$ Xing Liu,,${ }^{\text {b,d }}$ Anil Kumar, Larry Biehl, ${ }^{g}$ and P. Suresh C. Rao ${ }^{\text {be }}$}

${ }^{\mathrm{b}}$ Department of Agronomy, Purdue University, West Lafayette, Indiana

${ }^{c}$ Earth, Atmospheric and Planetary Sciences, Purdue University, West Lafayette, Indiana

${ }^{\mathrm{d}}$ Ecological Sciences and Engineering Interdisciplinary Graduate Program, Purdue University, West Lafayette, Indiana

e Lyles School of Civil Engineering, Purdue University, West Lafayette, Indiana

${ }^{\mathrm{f}}$ ESSIC, University of Maryland, College Park, Maryland

${ }^{\mathrm{g}}$ Information Technology at Purdue, Purdue University, West Lafayette, Indiana

Received 8 August 2016; in final form 31 January 2017

\begin{abstract}
A new, high-resolution $(4 \mathrm{~km})$, gridded land surface dataset produced with the Land Information System (LIS) is introduced, and the first set of synthesis of key hydroclimatic variables is reported. The dataset is produced over a 33-yr time period (1980-2012) for the U.S. Midwest with the intent to aid the agricultural community in understanding hydroclimatic impacts on crop production and decision-making in operational practices. While approximately 20 hydroclimatic variables are available through the LIS dataset, the focus here
\end{abstract}

Supplemental information related to this paper is available at the Journals Online website: http://dx.doi.org/10.1175/EI-D-16-0022.s1.

${ }^{\text {a }}$ Corresponding author: Elin M. Jacobs, ekarlsson@purdue.edu

DOI: $10.1175 /$ EI-D-16-0022.1 
Earth Interactions - Volume 21 (2017) - Paper No. 4 • Page 2

is on soil water content, soil temperature, and evapotranspiration. To assess the performance of the model, the LIS dataset is compared with in situ hydrometeorological observations across the study domain and with coarse-resolution reanalysis products [NARR, MERRA, and NLDAS-2 (phase 2 of the North American Land Data Assimilation System)]. In agricultural regions such as the U.S. Midwest, finescale hydroclimatic mapping that links the regional scale to the field scale is necessary. The new dataset provides this link as an intermediate-scale product that links point observations and coarse gridded datasets. In general, the LIS dataset compares well with in situ observations and coarser gridded products in terms of both temporal and spatial patterns, but cases of strong disagreement exist particularly in areas with sandy soils. The dataset is made available to the broader research community as an effort to fill the gap in spatial hydroclimatic data availability.

KEYWORDS: Physical meteorology and climatology; Evapotranspiration; Soil moisture; Soil temperature; Models and modeling; Data assimilation; Land surface model; Model evaluation

\section{Introduction}

Soil water storage and soil temperature are important components of landatmosphere interactions and critical variables in research fields such as hydrology, ecology, meteorology, and agriculture (Xia et al. 2013; Robock et al. 1998; Entekhabi et al. 2010; Seneviratne et al. 2010; Ochsner et al. 2013). Climate change and related changes in soil temperature and soil water content is likely to bring alterations to agricultural systems in terms of crop productivity, crop variety, and planting and harvest times (Southworth et al. 2000; Lobell et al. 2014; Challinor et al. 2014; Bollero et al. 1996). While hydroclimatic reanalysis products, including soil water and temperature, are available at very coarse resolutions, they are not aligned with land surface model or crop model interfaces. Crop models are used to predict yields and can help producers in decision-making based on climate scenarios. Climatic data are traditionally obtained from in situ observation stations, but coupling of hydrometeorological processes with crop models is becoming increasingly popular. For this, finescale hydrometeorological mapping that links the regional scale to the field scale is necessary (Hollinger and Isard 1994; Ines et al. 2013). Such products are currently lacking.

While several studies (e.g., Chaney et al. 2015; Livneh et al. 2013) have shown the importance of spatially and temporally continuous soil water and soil temperature data, observations are in many places still scarce. In recent years, monitoring of these variables has advanced through monitoring networks such as the USDA-NRCS Soil Climate Analysis Network (SCAN; Schaefer et al. 2007) and AmeriFlux (http://ameriflux.ornl.gov/) and databases such as the Texas A\&M University (TAMU) North American Soil Moisture Database (NASMDB; http:// soilmoisture.tamu.edu/Data/). In addition to in situ measurements, a number of remotely sensed soil water and soil temperature products are available, including Soil Moisture and Ocean Salinity (SMOS) mission (Kerr et al. 2010) and the recently launched Soil Moisture Active Passive (SMAP; Entekhabi et al. 2010). While these products cover large areas, the spatial resolution is often coarse (e.g., $35-50 \mathrm{~km}$ for SMOS, $10 \mathrm{~km}$ for SMAP) and measure only the top $5 \mathrm{~cm}$ of soil. This combined with the difficulty to validate these products make them unsuitable for 
Earth Interactions - Volume 21 (2017) • Paper No. 4 • Page 3

some applications requiring soil water storage dynamics in the entire root zone ( $\sim 0-100 \mathrm{~cm}$; Reichle et al. 2004; Ochsner et al. 2013). Land data assimilation systems (LDAS) integrate models and observations to give a best estimate of the land surface state in terms of water and energy storage and fluxes continuously in space and time. An LDAS provides information about initial conditions to land surface models (LSM) by using observational data, mainly retrieved from satellites, such that offline LSM runs are enabled. This approach minimizes errors and biases caused by numerical weather prediction (NWP) and atmospheric models (Houser 2003).

This study is a part of the multidisciplinary U.S. Department of Agriculture (USDA) Useful to Usable (U2U) project (http://www.agclimate4u.org; Prokopy et al. 2017), where the overall objective is to further our understanding of hydroclimatic variability and crop resiliency within the U.S. Corn Belt. One of the associated themes recognizes that currently available hydroclimatic information is either at a point scale (as in situ observations) or at a coarse grid scale (as reanalysis or remote sensing products) at $\Delta X=10-100 \mathrm{~km}$. The objective here was to create an intermediate-scale hydroclimatic product $(\Delta X=4 \mathrm{~km})$, which could be used for regional hydroclimatic and crop studies. Within this, an LDAS-based product including soil water, soil temperature, evapotranspiration, and turbulent fluxes at an intermediate resolution $(\Delta X=4 \mathrm{~km})$ for agroclimatic users was created. We describe the computational downscaling framework and the results of the initial assessment. Figure 1 shows a schematic of how this study connects the available hydroclimatic information with crop-climate studies. A number of other studies utilizing the dataset are underway through researchers within the U2U project as these data become available. Further documentation of the process and the data attributes, and evaluation of key meteorological variables, is available in a companion study (Liu et al. 2017). Here, we focus on the assessment of hydroclimatic variables, namely, soil water content, soil temperature, and evapotranspiration.

The remainder of the paper is organized as follows: In section 2, we describe the LIS model framework and configuration used to produce the 33-yr hydroclimatic dataset and the observational datasets and reanalysis products used for model output validation. In section 3 , we discuss the methodology for our analysis. In section 4 , we present and discuss the results of point validation against in situ measurements for different land use/land cover (LULC) and soil types within the study area, along with a comparison of the LIS dataset with existing coarser-scale reanalysis products for the 33-yr time period and discuss the role of stakeholders in developing this dataset. In section 5 , we provide a summary of our findings and propose future work and applications of the dataset.

\section{Data and methods}

In the setup of this study, we build off existing LDASs where two options were considered. Initial work was done with the National Center for Atmospheric Research (NCAR) High-Resolution LDAS (HRLDAS; http://www.ral.ucar.edu/ research/land/technology/hrldas.php; Chen et al. 2007) with parallel efforts with NASAs Land Information System (LIS; http://lis.gsfc.nasa.gov/; Kumar et al. 2006; Peters-Lidard et al. 2007; Kumar et al. 2008). Because our interest was to adapt remotely sensed products with the interface and multiple forcings available, 
Earth Interactions - Volume 21 (2017) • Paper No. 4 • Page 4

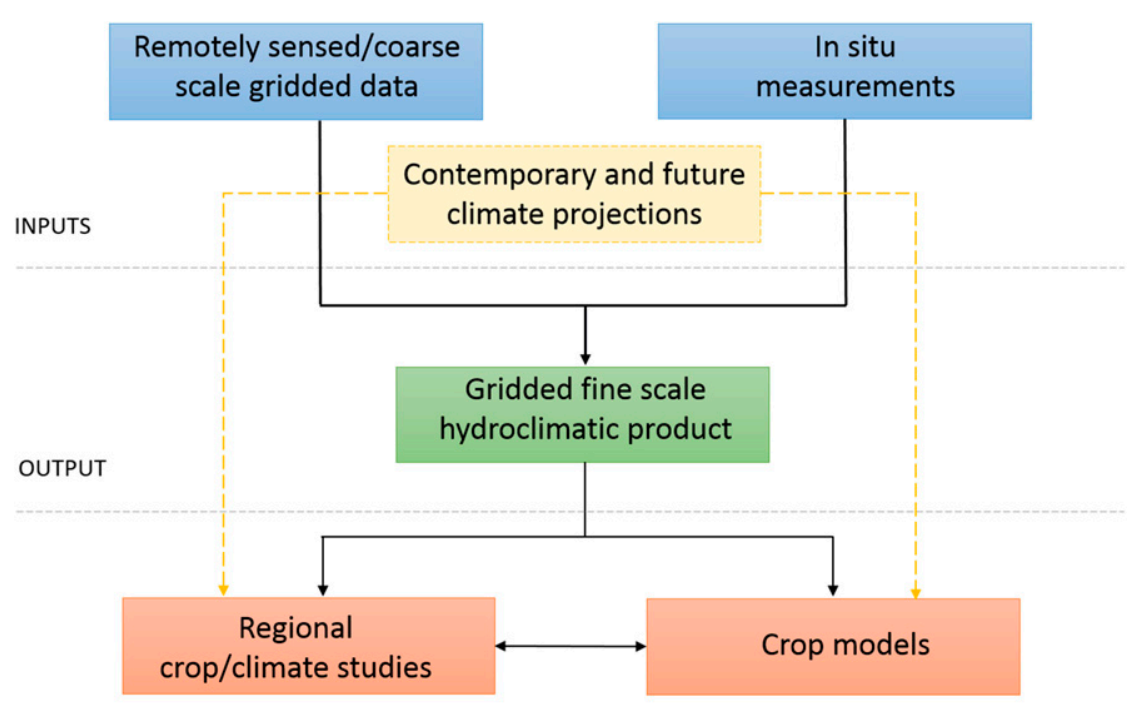

APPLICATIONS

Figure 1. Schematic showing the role of the new hydroclimatic dataset presented in this study. Currently, available hydroclimatic data products at a coarse, gridded scale and local point scale (blue boxes) are used as input to and/ or validation of the new dataset (green box). The dataset is then used as input to gridded crop models and as ubiquitous data in regional (U.S. Midwest) crop and climate studies (orange boxes). As an extension, climate projections can provide insights to future crop-climate trajectories (yellow box).

the NASA LIS framework was pursued further. The results discussed here and the dataset made available are produced using the LIS framework. While LIS is compatible with multiple LSMs and multiple forcing attributes, the choice of LSM was driven by our goal to interface in future studies the Noah LSM (Chen and Dudhia 2001; Ek 2003; Chen et al. 2007) with coupled crop models building off a regional climate perspective. Hence, Noah becomes the LSM of choice in terms of the land surface characterization within the hydroclimatic framework. The results presented here are dependent on the choice of this model and the embedded framework. Figure 2 shows the workflow adapted to the framework in this study. A detailed description and discussion of the various elements follows.

\subsection{Data assimilation framework and land surface model}

NASA's LIS was used as the data assimilation framework. LIS consists of a number of components, where the LIS core contains the LSM used to produce the output data. LIS also contains a module that provides tools to retrieve input data from various sources, including the initial conditions for the land surface and meteorological forcing data. Here, LIS, version 6.0, is configured using Noah, version 3.3, as the land surface model. The Noah model uses radiation, precipitation, pressure, humidity, and related information as hydrometeorological forcing 
Earth Interactions • Volume 21 (2017) • Paper No. 4 • Page 5

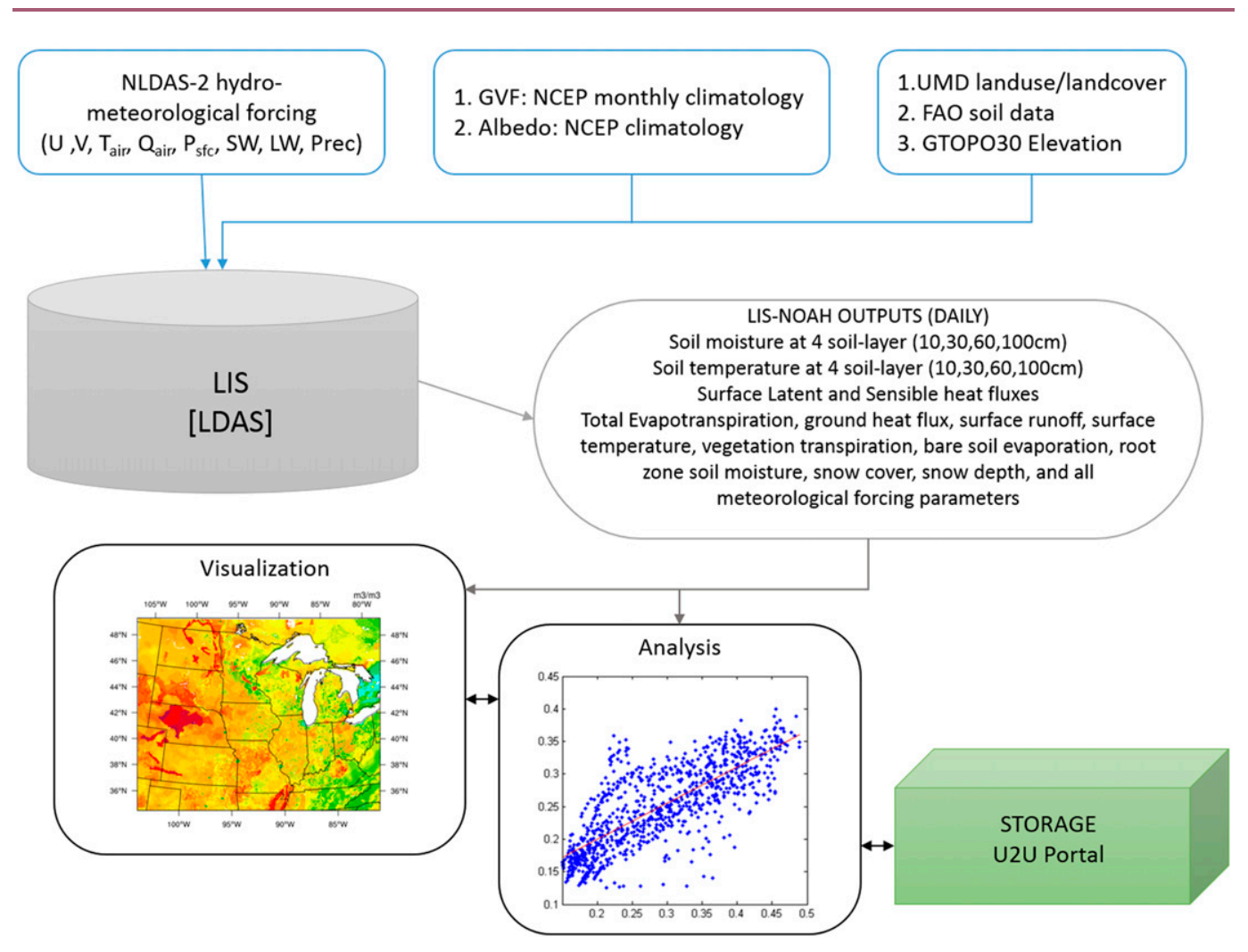

Figure 2. Schematic of the workflow adapted to produce, analyze, and store the hydroclimatic dataset. Hydrometeorological forcings include winds in $U$ and $V$ direction, air temperature $T_{\text {air }}$, humidity $Q_{\text {air, }}$ surface pressure $P_{\mathrm{sfc}}$, shortwave (SW) and longwave (LW) radiation, and precipitation (Prec). See text for detailed information on input data. LIS produces approximately 30 output variables at a daily time step. A list of all variables is available in the appendix. An extensive visual and analytical quality assessment of the dataset is performed. The dataset is stored in its entirety at the U2U data portal. Additional information on data storage and accessibility is provided in the text.

and converts it to soil water, soil temperature, evapotranspiration, fluxes, interception, and other variables. Figure 3 shows the details of the LIS-Noah framework. The core model was applied over a domain that roughly encompasses the region covering the majority of the U.S. Corn Belt (Figure 4a). For completeness of the domain a few additional states had to be included. The domain was centered at $41.89893^{\circ}$ latitude and $90.86097^{\circ}$ longitude and had a grid spacing $(\Delta X, \Delta Y)$ of $4 \mathrm{~km}$. The choice of a $4-\mathrm{km}$ grid spacing was dictated by the availability of precipitation datasets [e.g., NCEP/Environmental Modeling Center (EMC) Stage IV data; Baldwin and Mitchell 1996] and some initial work involving LDAS indicating that the results were most stable associated with a 4-km grid spacing. In addition, when running the LDAS in a coupled mode for regional climate studies or meteorological studies with the Weather Research and Forecasting (WRF) Model, 


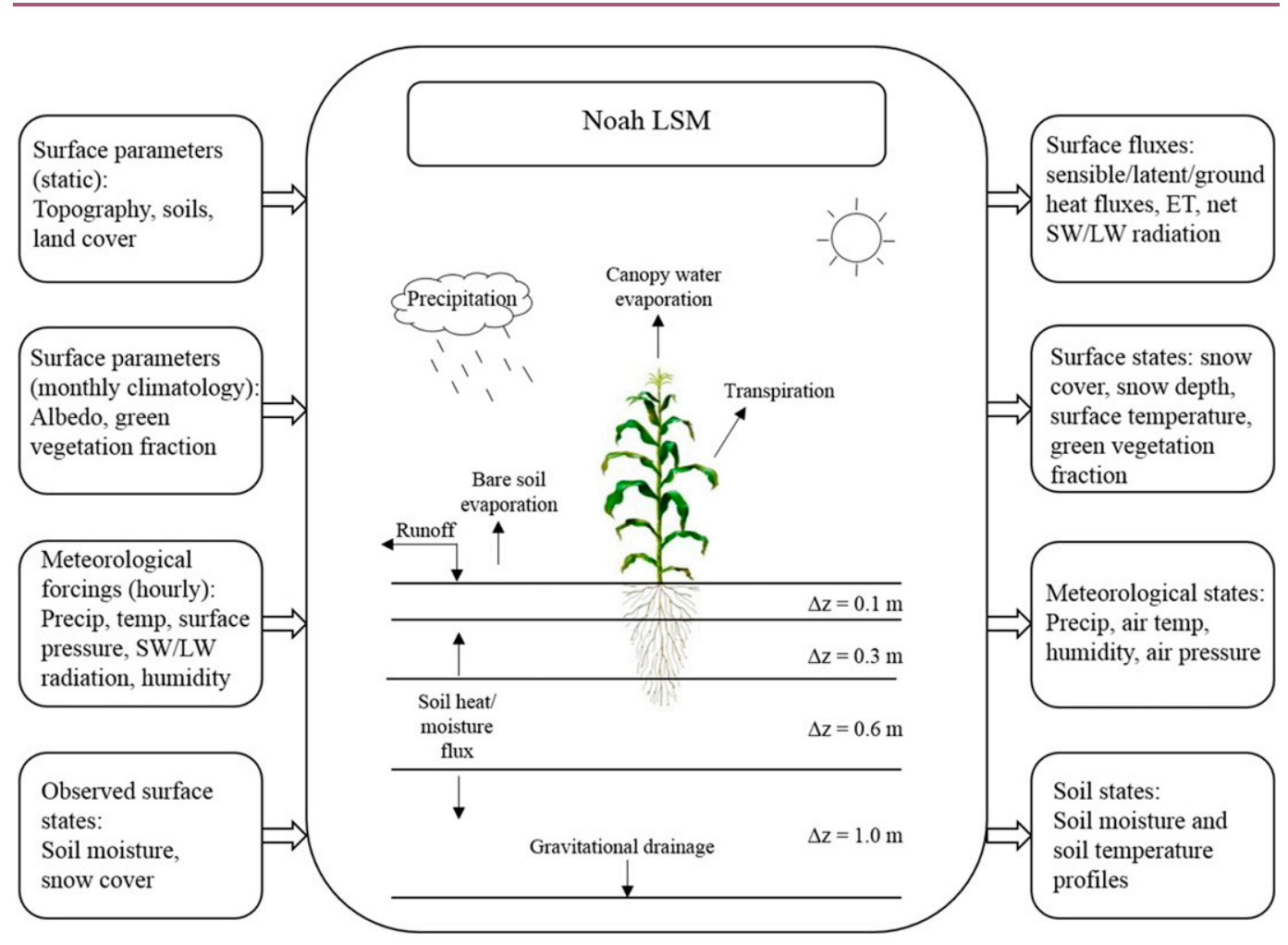

Figure 3. The LIS-Noah framework. Input information includes static land surface information (topography, soils, land use), nonstationary surface data (albedo, green vegetation fraction, snow cover), and hydrometeorological forcings. The Noah model is configured with a total soil depth of $2 \mathrm{~m}$, divided into four layers. See the text for a description of model physics. Model outputs include surface fluxes and states, soil states, and downscaled meteorological states.

results are also most accurate with the 4-km grid spacing used in this analysis (Schwartz et al. 2009). The soil texture, vegetation characteristics, and land-use/ land-cover datasets have an important role in the evolution of the hydroclimatology of a given region. Figures $4 \mathrm{c}$ and $4 \mathrm{~d}$ show the soil texture and land use/land cover dominant within the Noah grid. Soil texture is for the top $30 \mathrm{~cm}$, and the land use/ land cover is for the prominent $(>50 \%)$ area within the grid. The model adopts a phenology based on prior MODIS NDVI datasets. The insert in Figure 4b shows the intra-annual temporal changes of greenness vegetation fraction (GVF) that typically show green-up around March-April, a peak around June, and then a dieoff around August-September. This has implications in terms of the vegetation input to the Noah model and the partitioning of energy as well as the demand that is required for water and energy fluxes.

Noah is based on a combination of the Penman potential evaporation method of Mahrt and Ek (1984), the two-layer soil model of Mahrt and Pan (1984), and the canopy model of Pan and Mahrt (1987), with the addition of the more complex canopy resistance formulations of Noilhan and Planton (1989) and 


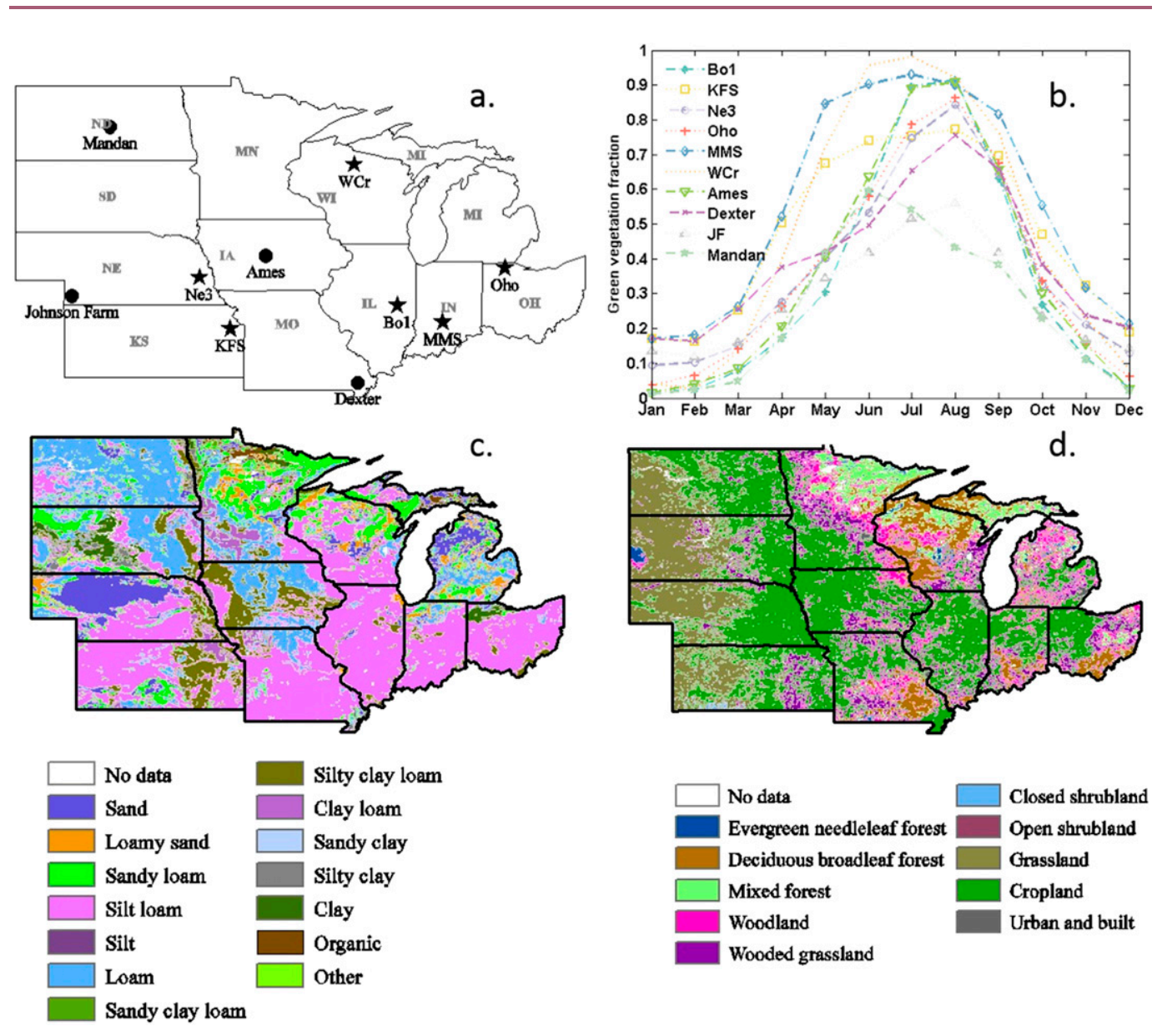

Figure 4. Map of the study domain located in the U.S. Midwest. (a) The location of in situ sites used for model validation. Dots indicate SCAN sites, and stars indicate Ameriflux sites. Refer to Table 1 for site information. (b) The intraannual temporal changes in green vegetation fraction for each site in (a). (c),(d) The soil and land-cover information, respectively, for the domain. This information is also used as input to the LIS-Noah framework.

Jacquemin and Noilhan (1990). Noah here uses a total soil depth of $2 \mathrm{~m}$ divided into four soil layers $(0-10,10-40,40-100$, and $100-200 \mathrm{~cm})$, where roots are present in the top three layers (all four layers for forested vegetation classes). The soil texture is assumed to be homogenous for the entire soil column based on the mapped texture of the top $30 \mathrm{~cm}$. The hydrologic properties associated with each soil texture are based on the analysis of Cosby et al. (1984). The bottom layer acts as a reservoir with gravitational drainage at the bottom. For further details, refer to Chen and Dudhia (2001). Soil water content and soil temperature are simulated at the midpoint of each layer, that is, 5, 25, 70, and $150 \mathrm{~cm}$. Here, phase 2 of the North American Land Data Assimilation System (NLDAS-2; Xia et al. 2012) is used as meteorological forcing. The forcing data are in $18^{\circ}$ grid spacing and range from 1 January 1979 to 31 December 2012 at an 
Earth Interactions - Volume 21 (2017) • Paper No. 4 • Page 8

hourly temporal resolution. Additional inputs including albedo and greenness from the National Centers for Environmental Prediction (NCEP), 1-km University of Maryland (UMD) land cover with 13 vegetation classifications (Hansen et al. 2000), 1-km Food and Agriculture Organization of the United Nations (FAO)/U.S. General Soil Map (STATSGO2) soil texture classifications (Reynolds et al. 2000) and GTOPO30 elevation data. Soil and vegetation data were aggregated using the most predominant type to the $4-\mathrm{km}$ grid.

\subsection{Observations and reanalysis products}

Locations of the in situ sites that are used for comparing the model results and the LIS aspects with available soil water are included in Figure 4a. While efforts to produce regional and global spatially distributed observed soil water data are currently underway through the NASMDB and Global Soil Moisture Data Bank (Robock et al. 2000), the intent here is to provide an overview of model performance; thus, sites related to different biomes and land use/land cover were selected roughly spaced around the domain. We use in situ observations from six AmeriFlux (http://ameriflux.ornl.gov/) sites and four SCAN (Schaefer et al. 2007) sites for comparison with the LIS output. The attributes for these sites are given in Table 1, including the datasets and time periods of available records. Data were checked for quality and consistency, and outliers and erroneous data were marked as missing. If there were any missing days within a month, that entire month was considered as missing. Previous studies (Hu and Feng 2004; Xia et al. 2013) have used a variation of this method, where months with more than five consecutive days missing were excluded. In the AmeriFlux and SCAN datasets, it was rare to have only a few days missing, hence the strict rule to exclude any month with missing data. The time period covered varies between sites and does not cover the entire simulated period.

We use three existing, coarser-resolution reanalysis datasets for comparison with LIS and observations at the point scale and over the entire study domain. NASA's Modern-Era Retrospective Analysis for Research and Applications (MERRA; Rienecker et al. 2011; Reichle et al. 2011) is available from 1979 to present at hourly time steps and at a spatial resolution of $1 / 2{ }^{\circ}$ in latitude and $2 / 3^{\circ}$ in longitude. Soil temperature is available for six layers, and soil water content is available for the top soil layer $(2 \mathrm{~cm})$ and for the root zone $(100 \mathrm{~cm})$ using the Catchment land surface model. The NCEP-NCAR North American Regional Reanalysis (NARR; Mesinger et al. 2006) is available from 1979 to present at $32-\mathrm{km}$ resolution with soil water and soil temperature at four depths $(0,10,40$, $100 \mathrm{~cm})$, with one additional soil temperature depth $(800 \mathrm{~cm})$, using Noah LSM. NLDAS-2 (Xia et al. 2012, 2013) is available from 1979 to present at $1 / 8^{\circ}$ latitude-longitude resolution, with Noah-based soil moisture and temperature at four depths $(0,10,40,100 \mathrm{~cm})$. For all comparisons with reanalysis products, we use monthly averaged data for 1980-2012. The choice of time period was driven by the starting date of the forcing dataset (1979), availability of in situ observations, and our desire to include the severe drought of 2012 in our analysis. 


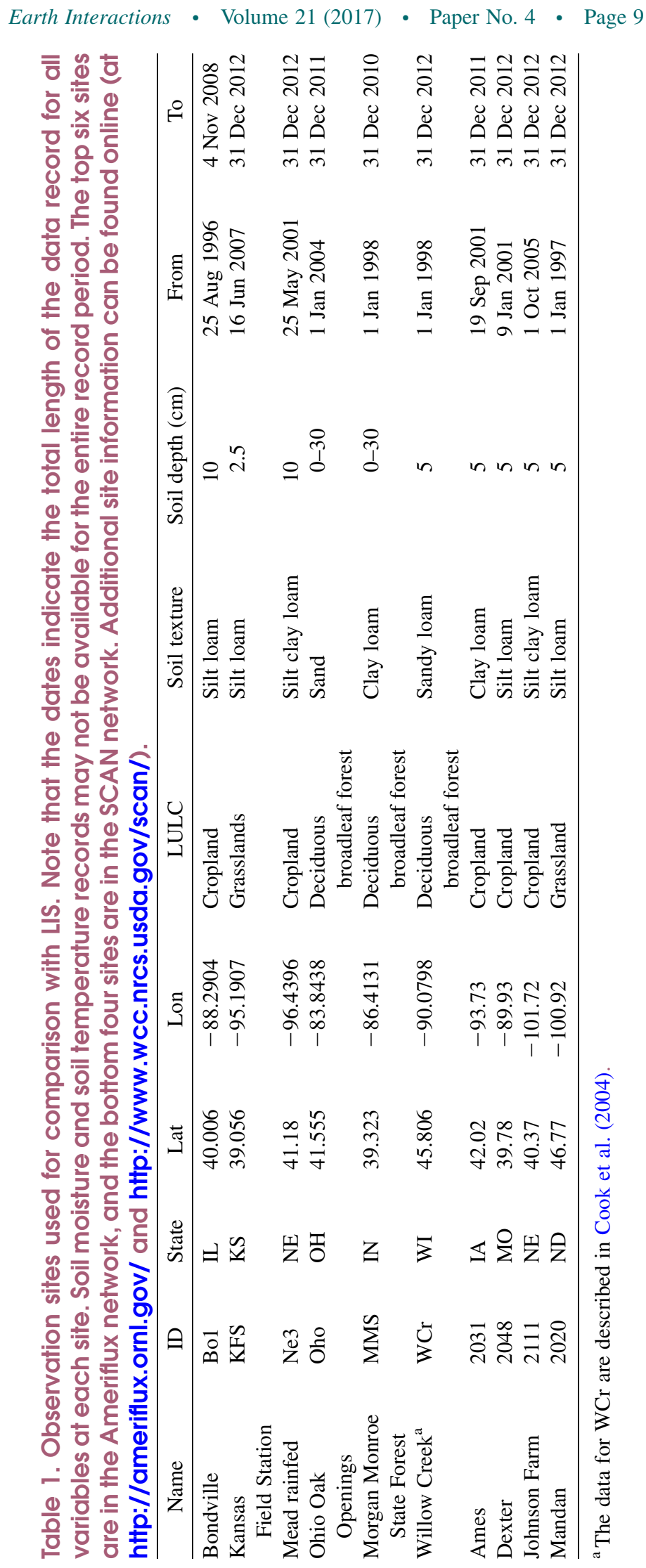


Earth Interactions - Volume 21 (2017) • Paper No. 4 • Page 10

Table 2. Summary statistics for top layer, growing season, volumetric soil water content $\theta\left(\mathrm{m}^{3} \mathrm{~m}^{-3}\right)$, normalized soil water content $s(-)$ and soil temperature $\left({ }^{\circ} \mathrm{C}\right)$, including mean, 95\% confidence interval $(\mathrm{Cl})$ and $\mathrm{CV}$ for all datasets and sites.

\begin{tabular}{|c|c|c|c|c|c|c|c|c|c|c|}
\hline \multirow[b]{2}{*}{ Site } & \multirow[b]{2}{*}{ Product } & \multicolumn{3}{|c|}{ Vol. soil water content $\theta$} & \multicolumn{3}{|c|}{ Norm. soil water content $s$} & \multicolumn{3}{|c|}{ Soil temperature } \\
\hline & & mean & $95 \% \mathrm{CI}$ & $\mathrm{CV}$ & Mean & $95 \% \mathrm{CI}$ & $\mathrm{CV}$ & Mean & $95 \% \mathrm{CI}$ & $\mathrm{CV}$ \\
\hline \multirow[t]{5}{*}{ Bo1 } & Observed & 0.30 & 0.03 & 0.20 & 0.53 & 0.13 & 0.56 & 18.88 & 1.36 & 0.26 \\
\hline & LIS & 0.30 & 0.01 & 0.18 & 0.62 & 0.03 & 0.37 & 18.65 & 0.57 & 0.24 \\
\hline & NARR & 0.27 & 0.01 & 0.29 & 0.56 & 0.04 & 0.51 & 17.26 & 0.47 & 0.21 \\
\hline & NLDAS-2 & 0.27 & 0.00 & 0.11 & 0.67 & 0.03 & 0.30 & 17.97 & 0.60 & 0.26 \\
\hline & MERRA & 0.32 & 0.01 & 0.16 & 0.58 & 0.03 & 0.45 & 18.45 & 0.71 & 0.30 \\
\hline \multirow[t]{5}{*}{ KFS } & Observed & 0.26 & 0.02 & 0.19 & 0.45 & 0.13 & 0.63 & 21.58 & 1.84 & 0.22 \\
\hline & LIS & 0.28 & 0.01 & 0.21 & 0.52 & 0.03 & 0.46 & 19.56 & 0.69 & 0.27 \\
\hline & NARR & 0.24 & 0.01 & 0.31 & 0.44 & 0.04 & 0.63 & 17.48 & 0.57 & 0.25 \\
\hline & NLDAS-2 & 0.31 & 0.00 & 0.08 & 0.66 & 0.02 & 0.28 & 18.06 & 0.70 & 0.30 \\
\hline & MERRA & 0.30 & 0.01 & 0.18 & 0.55 & 0.03 & 0.40 & 19.53 & 0.70 & 0.28 \\
\hline \multirow[t]{5}{*}{$\mathrm{Ne} 3$} & Observed & 0.31 & 0.01 & 0.18 & 0.66 & 0.05 & 0.33 & 18.43 & 1.22 & 0.30 \\
\hline & LIS & 0.26 & 0.01 & 0.19 & 0.52 & 0.03 & 0.41 & 19.14 & 0.70 & 0.28 \\
\hline & NARR & 0.22 & 0.01 & 0.31 & 0.41 & 0.04 & 0.67 & 17.27 & 0.57 & 0.25 \\
\hline & NLDAS-2 & 0.29 & 0.00 & 0.12 & 0.65 & 0.02 & 0.29 & 17.49 & 0.71 & 0.31 \\
\hline & MERRA & 0.27 & 0.01 & 0.18 & 0.51 & 0.03 & 0.40 & 18.41 & 0.75 & 0.31 \\
\hline \multirow[t]{5}{*}{ Oho } & Observed & 0.06 & 0.00 & 0.26 & 0.54 & 0.08 & 0.50 & 18.95 & 1.37 & 0.23 \\
\hline & LIS & 0.33 & 0.00 & 0.06 & 0.66 & 0.02 & 0.27 & 18.22 & 0.64 & 0.27 \\
\hline & NARR & 0.27 & 0.01 & 0.28 & 0.56 & 0.04 & 0.50 & 15.55 & 0.55 & 0.27 \\
\hline & NLDAS-2 & 0.13 & 0.00 & 0.11 & 0.65 & 0.02 & 0.29 & 17.01 & 0.66 & 0.30 \\
\hline & MERRA & 0.27 & 0.01 & 0.15 & 0.57 & 0.03 & 0.39 & 16.64 & 0.67 & 0.31 \\
\hline \multirow[t]{5}{*}{ MMS } & Observed & 0.35 & 0.02 & 0.24 & 0.64 & 0.08 & 0.45 & 16.44 & 1.19 & 0.21 \\
\hline & LIS & 0.34 & 0.00 & 0.11 & 0.64 & 0.03 & 0.34 & 18.28 & 0.59 & 0.25 \\
\hline & NARR & 0.29 & 0.01 & 0.25 & 0.57 & 0.03 & 0.45 & 18.63 & 0.61 & 0.25 \\
\hline & NLDAS-2 & 0.29 & 0.00 & 0.06 & 0.70 & 0.02 & 0.26 & 17.31 & 0.62 & 0.28 \\
\hline & MERRA & 0.34 & 0.01 & 0.15 & 0.69 & 0.03 & 0.33 & 17.84 & 0.64 & 0.28 \\
\hline \multirow[t]{5}{*}{$\mathrm{WCr}$} & Observed & 0.33 & 0.01 & 0.13 & 0.60 & 0.06 & 0.36 & 12.88 & 0.86 & 0.34 \\
\hline & LIS & 0.30 & 0.00 & 0.11 & 0.41 & 0.02 & 0.37 & 12.69 & 0.63 & 0.38 \\
\hline & NARR & 0.31 & 0.01 & 0.14 & 0.56 & 0.02 & 0.30 & 12.77 & 0.62 & 0.38 \\
\hline & NLDAS-2 & 0.26 & 0.00 & 0.07 & 0.65 & 0.03 & 0.32 & 10.78 & 0.64 & 0.46 \\
\hline & MERRA & 0.29 & 0.01 & 0.16 & 0.57 & 0.03 & 0.42 & 13.15 & 0.75 & 0.44 \\
\hline \multirow[t]{5}{*}{ Ames } & Observed & 0.32 & 0.02 & 0.24 & 0.55 & 0.06 & 0.45 & 12.67 & 1.37 & 0.40 \\
\hline & LIS & 0.28 & 0.01 & 0.19 & 0.52 & 0.03 & 0.45 & 17.51 & 0.63 & 0.28 \\
\hline & NARR & 0.26 & 0.01 & 0.25 & 0.51 & 0.03 & 0.49 & 18.03 & 0.65 & 0.28 \\
\hline & NLDAS-2 & 0.24 & 0.00 & 0.10 & 0.57 & 0.03 & 0.37 & 16.50 & 0.66 & 0.31 \\
\hline & MERRA & 0.25 & 0.01 & 0.19 & 0.45 & 0.03 & 0.49 & 16.74 & 0.73 & 0.34 \\
\hline \multirow[t]{5}{*}{ Dexter } & Observed & 0.19 & 0.01 & 0.33 & 0.43 & 0.05 & 0.58 & 20.48 & 1.64 & 0.42 \\
\hline & LIS & 0.35 & 0.00 & 0.09 & 0.69 & 0.03 & 0.29 & 22.78 & 0.66 & 0.22 \\
\hline & NARR & 0.28 & 0.01 & 0.25 & 0.52 & 0.03 & 0.51 & 22.37 & 0.66 & 0.23 \\
\hline & NLDAS-2 & 0.31 & 0.00 & 0.11 & 0.71 & 0.02 & 0.25 & 20.97 & 0.65 & 0.24 \\
\hline & MERRA & 0.33 & 0.01 & 0.12 & 0.60 & 0.03 & 0.38 & 20.19 & 0.64 & 0.25 \\
\hline \multirow[t]{5}{*}{$\mathrm{JF}$} & Observed & 0.22 & 0.02 & 0.27 & 0.47 & 0.10 & 0.53 & 16.27 & 1.82 & 0.35 \\
\hline & LIS & 0.22 & 0.00 & 0.14 & 0.47 & 0.03 & 0.42 & 20.28 & 0.77 & 0.29 \\
\hline & NARR & 0.19 & 0.01 & 0.21 & 0.38 & 0.03 & 0.57 & 21.14 & 0.79 & 0.29 \\
\hline & NLDAS-2 & 0.23 & 0.00 & 0.13 & 0.60 & 0.03 & 0.35 & 17.98 & 0.80 & 0.34 \\
\hline & MERRA & 0.17 & 0.00 & 0.13 & 0.58 & 0.03 & 0.33 & 18.51 & 0.79 & 0.33 \\
\hline
\end{tabular}


Earth Interactions - Volume 21 (2017) • Paper No. 4 • Page 11

Table 2. (Continued)

\begin{tabular}{|c|c|c|c|c|c|c|c|c|c|c|}
\hline \multirow[b]{2}{*}{ Site } & \multirow[b]{2}{*}{ Product } & \multicolumn{3}{|c|}{ Vol. soil water content $\theta$} & \multicolumn{3}{|c|}{ Norm. soil water content $s$} & \multicolumn{3}{|c|}{ Soil temperature } \\
\hline & & mean & $95 \% \mathrm{CI}$ & $\mathrm{CV}$ & Mean & $95 \% \mathrm{CI}$ & $\mathrm{CV}$ & Mean & $95 \% \mathrm{CI}$ & $\mathrm{CV}$ \\
\hline \multirow[t]{5}{*}{$\overline{\text { Mandan }}$} & Observed & 0.19 & 0.01 & 0.33 & 0.43 & 0.05 & 0.58 & 20.48 & 1.64 & 0.42 \\
\hline & LIS & 0.22 & 0.00 & 0.17 & 0.36 & 0.02 & 0.46 & 16.89 & 0.81 & 0.37 \\
\hline & NARR & 0.21 & 0.01 & 0.24 & 0.33 & 0.03 & 0.60 & 16.74 & 0.82 & 0.38 \\
\hline & NLDAS-2 & 0.20 & 0.00 & 0.14 & 0.50 & 0.03 & 0.38 & 14.29 & 0.78 & 0.42 \\
\hline & MERRA & 0.19 & 0.00 & 0.16 & 0.46 & 0.02 & 0.35 & 15.81 & 0.88 & 0.43 \\
\hline
\end{tabular}

\section{Data processing}

The processed LIS data were initially visualized by different U2U team members, including climatologists, meteorologists, hydrologists, and agronomists, both in terms of singular plots and multiple spatial plots and animations, and an initial effort of quality assurance was undertaken. The data were then processed further in terms of evaluation of possible outliers and synthesis of any systematic biases that emerged. In doing so, one interesting feature was noted; there was an unusually high bias in soil water particularly for winter conditions. Principal investigators (PIs) for the in situ networks placed very low confidence on soil water measurements under winter conditions due to freezing and thawing. While previous studies have shown that Noah has issues with snow-related processes (e.g., Livneh et al. 2010), it is unclear whether these biases for wintertime soil water are indeed due to formulation issues within the model or whether they are from in situ measurement errors. In conducting the rest of the synthesis and analysis, and also consistent with the period of interest, which is the growing season (here defined as the months of April through October), the attention is focused on the period of nonfrozen soil characteristics. This is an example of a systematic bias that was noted in the assessment. Another bias that we noted was the disparity that may emerge due to the lack of availability of regional-scale soil texture information versus the information available at a specific site and those being used within reanalysis frameworks.

\section{Resullts and discussion}

Table 2 reports the summary statistics [mean, 95\% confidence intervals, and coefficient of variation (CV)] of growing season volumetric soil water content $\theta$, normalized soil water content $s$, and soil temperature for all sites and datasets. There are clear differences in means between datasets, but these differences do not appear to be systematic. The variability, as measured by $\mathrm{CV}$, is relatively small for all three variables. Soil temperature is of agronomic interest both from the perspective of frost (Sinha and Cherkauer 2008) as well as larger-scale growing degree-day (GDD) assessments (Bollero et al. 1996) for conducting crop studies. Figure 5 shows the time series of soil temperature obtained from the different analyses and in situ observations at a monthly time step for the entire year. The results are in strong agreement between in situ measurements and modeled values as well as with the coarser-resolution reanalysis products. Figure 6 shows observed growing season temperature plotted against the modeled datasets at each site, with linear regressions $(y=a x \pm b)$ fitted to each data product. Here, $a \neq 1$ indicates a 


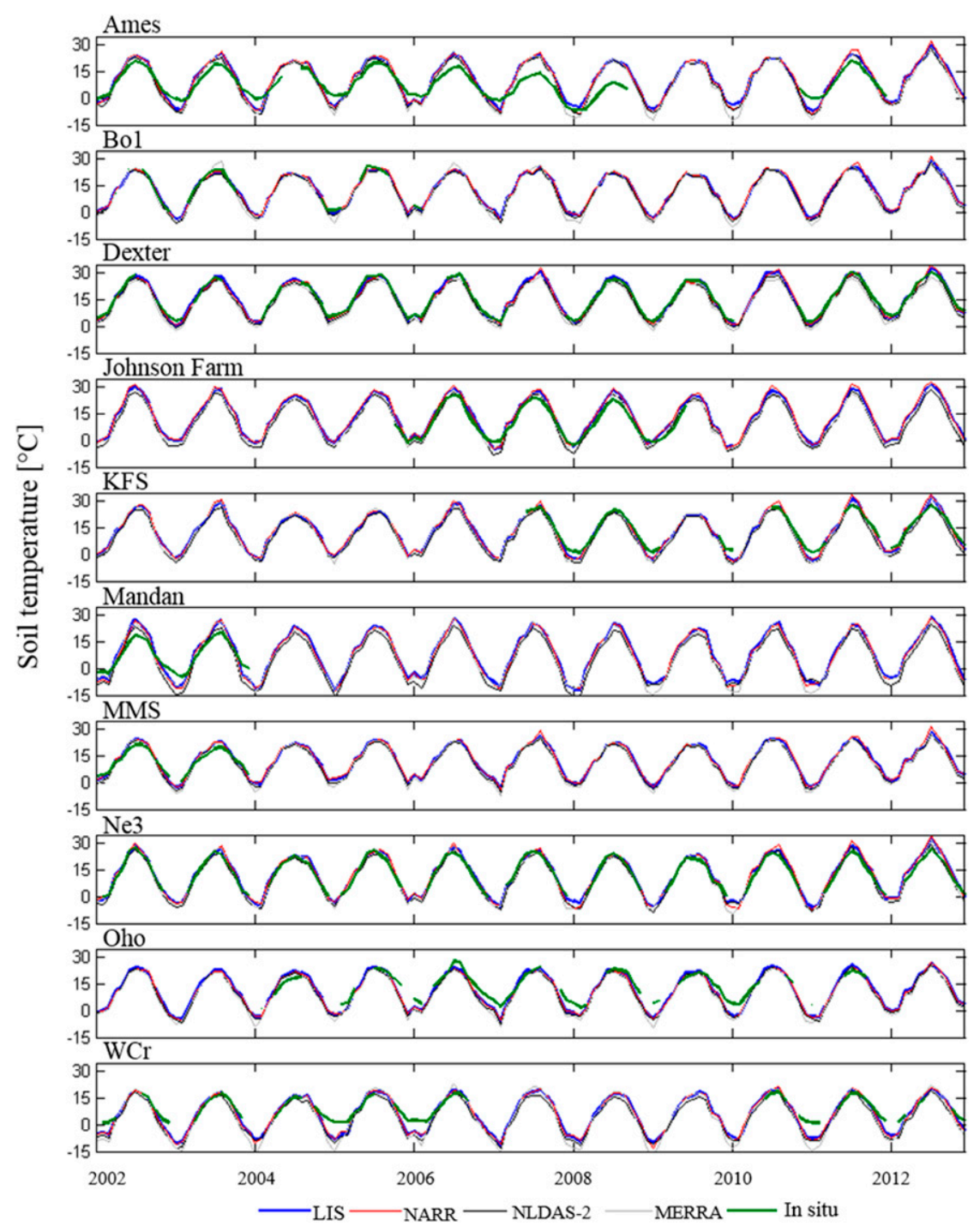

Figure 5. Time series of monthly averaged top layer soil temperature for 10 sites. For the gridded products (LIS, NARR, NLDAS-2, and MERRA), the time series of the grid corresponding to the in situ site is shown.

model failure, $b$ is an index of model bias, and the coefficient of determination $R^{2}$ is a measure of randomness. Parameter and $R^{2}$ values are reported in Table 3 . The parameter $a$ is close to 1 for soil temperature in most cases; however, parameter $b$ indicates that all models tend to under- and/or overestimate soil temperatures as compared to observations. Generally, all models under- or overestimate the temperature at a specific site, but there are exceptions (at, e.g., Bo1 and Oho). LIS and NARR are generally simulated at higher temperatures than NLDAS-2 and MERRA. Ames stands out as performing poorly in simulating soil temperature, where it is overestimated by all models. This could be due to the monitoring 
Earth Interactions - Volume 21 (2017) • Paper No. 4 • Page 13

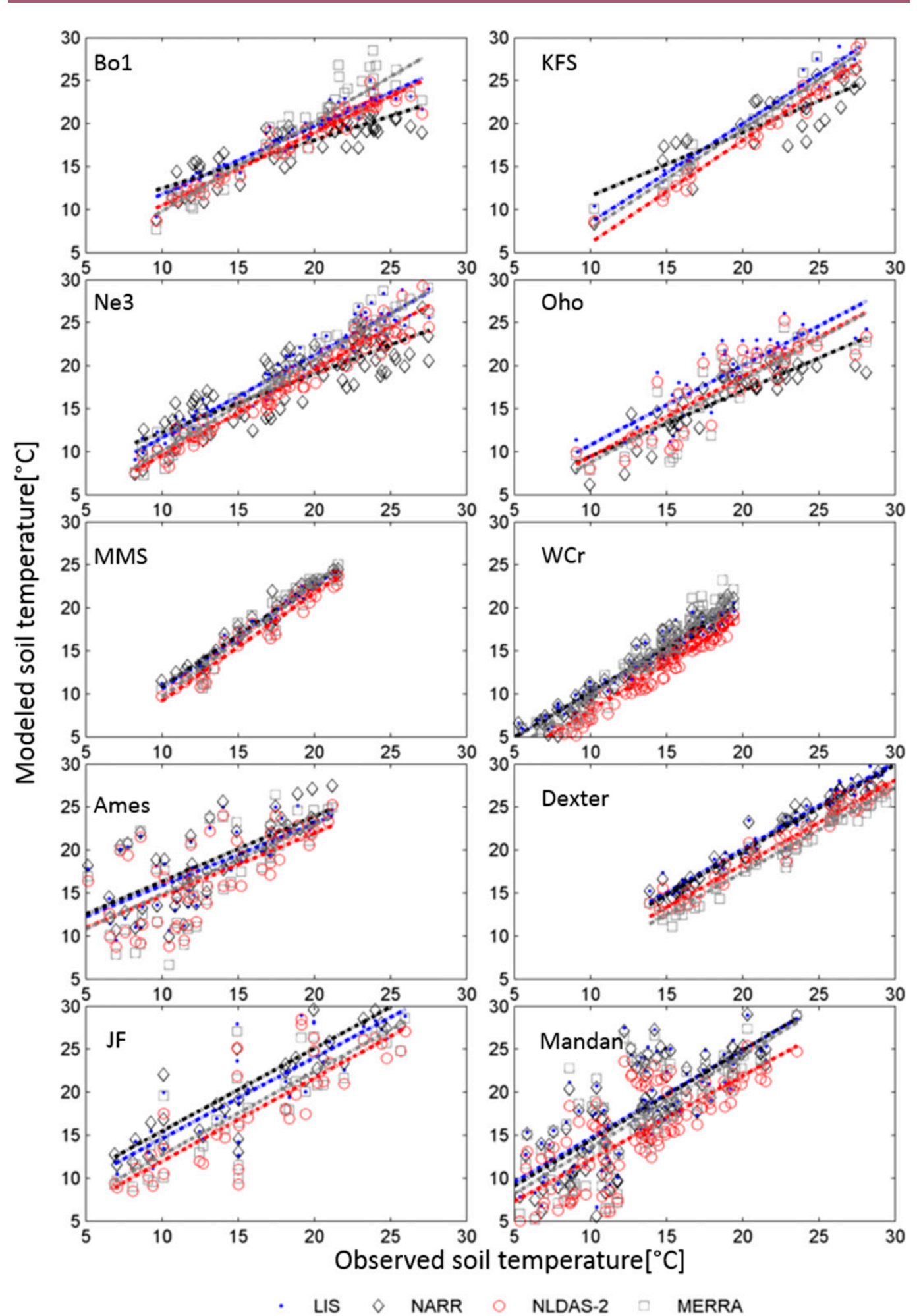

Figure 6. Observed soil temperature vs the four modeled datasets at each site. Dashed lines show linear regression fits to the data where the colors correspond to the color of the symbol for each dataset. 
Earth Interactions - Volume 21 (2017) • Paper No. 4 • Page 14

Table 3. Parameter values for linear regression fits $(y=a \pm b x)$ to growing season volumetric soil water content $\theta\left(\mathrm{m}^{3} \mathrm{~m}^{-3}\right)$, normalized soil water content $s(-)$, and soil temperature $\left({ }^{\circ} \mathrm{C}\right)$ of each model product to in situ observations. Coefficients of determination $R^{2}$ are also reported.

\begin{tabular}{|c|c|c|c|c|c|c|c|c|c|c|}
\hline \multirow[b]{2}{*}{ Site } & \multirow[b]{2}{*}{ Product } & \multicolumn{3}{|c|}{$\begin{array}{c}\text { Volumetric soil water } \\
\text { content } \theta\end{array}$} & \multicolumn{3}{|c|}{$\begin{array}{l}\text { Normalized soil water } \\
\text { content } s\end{array}$} & \multicolumn{3}{|c|}{ Soil temperature } \\
\hline & & $a$ & $b$ & $R^{2}$ & $a$ & $b$ & $R^{2}$ & $a$ & $b$ & $R^{2}$ \\
\hline \multirow[t]{4}{*}{ Bo1 } & LIS & 0.73 & 0.09 & 0.60 & 0.61 & 0.33 & 0.60 & 0.79 & 3.89 & 0.92 \\
\hline & NARR & 1.01 & -0.01 & 0.61 & 0.72 & 0.24 & 0.61 & 0.56 & 6.86 & 0.71 \\
\hline & NLDAS & 0.38 & 0.16 & 0.53 & 0.53 & 0.40 & 0.53 & 0.85 & 2.05 & 0.94 \\
\hline & MERRA & 0.75 & 0.08 & 0.56 & 0.77 & 0.10 & 0.56 & 1.04 & -0.61 & 0.88 \\
\hline \multirow[t]{4}{*}{ KFS } & LIS & 0.77 & 0.03 & 0.62 & 0.56 & 0.06 & 0.62 & 1.15 & -3.02 & 0.93 \\
\hline & NARR & 0.53 & 0.02 & 0.33 & 0.35 & -0.03 & 0.33 & 0.74 & 4.19 & 0.69 \\
\hline & NLDAS & 0.59 & 0.14 & 0.76 & 0.75 & 0.16 & 0.76 & 1.19 & -5.80 & 0.97 \\
\hline & MERRA & 0.78 & 0.06 & 0.53 & 0.57 & 0.15 & 0.53 & 1.16 & -3.79 & 0.93 \\
\hline \multirow[t]{4}{*}{$\mathrm{Ne} 3$} & LIS & 0.64 & 0.05 & 0.59 & 0.67 & 0.03 & 0.59 & 0.96 & 2.00 & 0.93 \\
\hline & NARR & 0.79 & -0.04 & 0.48 & 0.79 & -0.19 & 0.48 & 0.68 & 5.45 & 0.73 \\
\hline & NLDAS & 0.48 & 0.14 & 0.52 & 0.64 & 0.20 & 0.52 & 1.00 & -0.36 & 0.95 \\
\hline & MERRA & 0.52 & 0.10 & 0.48 & 0.55 & 0.07 & 0.48 & 1.06 & -0.49 & 0.94 \\
\hline \multirow[t]{4}{*}{ Oho } & LIS & 0.60 & 0.30 & 0.39 & 0.33 & 0.53 & 0.39 & 0.92 & 1.55 & 0.76 \\
\hline & NARR & 2.96 & 0.11 & 0.42 & 0.66 & 0.28 & 0.42 & 0.76 & 1.80 & 0.77 \\
\hline & NLDAS & 0.82 & 0.08 & 0.77 & 0.65 & 0.33 & 0.77 & 0.93 & 0.16 & 0.74 \\
\hline & MERRA & 1.60 & 0.17 & 0.44 & 0.52 & 0.32 & 0.44 & 0.96 & -0.83 & 0.76 \\
\hline \multirow[t]{4}{*}{ MMS } & LIS & 0.44 & 0.19 & 0.77 & 0.72 & 0.21 & 0.77 & 1.20 & -1.42 & 0.98 \\
\hline & NARR & 0.75 & 0.03 & 0.67 & 0.76 & 0.09 & 0.67 & 1.20 & -1.09 & 0.97 \\
\hline & NLDAS & 0.21 & 0.21 & 0.72 & 0.60 & 0.32 & 0.72 & 1.25 & -3.33 & 0.95 \\
\hline & MERRA & 0.50 & 0.17 & 0.69 & 0.65 & 0.31 & 0.69 & 1.32 & -3.58 & 0.93 \\
\hline \multirow[t]{4}{*}{ WCr } & LIS & 0.30 & 0.20 & 0.24 & 0.27 & 0.27 & 0.24 & 1.05 & -0.28 & 0.96 \\
\hline & NARR & 0.53 & 0.13 & 0.37 & 0.41 & 0.31 & 0.37 & 1.06 & -0.38 & 0.95 \\
\hline & NLDAS & -0.06 & 0.29 & 0.03 & -0.15 & 0.77 & 0.03 & 1.08 & -2.73 & 0.96 \\
\hline & MERRA & 0.69 & 0.06 & 0.51 & 0.75 & 0.13 & 0.51 & 1.24 & -2.65 & 0.94 \\
\hline \multirow[t]{4}{*}{ Ames } & LIS & 0.47 & 0.12 & 0.50 & 0.64 & 0.14 & 0.50 & 0.72 & 8.66 & 0.59 \\
\hline & NARR & 0.52 & 0.08 & 0.45 & 0.61 & 0.12 & 0.45 & 0.76 & 8.78 & 0.59 \\
\hline & NLDAS & 0.19 & 0.17 & 0.43 & 0.52 & 0.27 & 0.43 & 0.73 & 7.30 & 0.54 \\
\hline & MERRA & 0.37 & 0.11 & 0.58 & 0.53 & 0.06 & 0.58 & 0.81 & 6.79 & 0.53 \\
\hline \multirow[t]{4}{*}{ Dexter } & LIS & 0.25 & 0.30 & 0.45 & 0.42 & 0.53 & 0.45 & 1.01 & -0.07 & 0.96 \\
\hline & NARR & 0.77 & 0.12 & 0.42 & 0.72 & 0.17 & 0.42 & 1.01 & -0.36 & 0.94 \\
\hline & NLDAS & 0.34 & 0.24 & 0.58 & 0.44 & 0.52 & 0.58 & 0.99 & -1.42 & 0.96 \\
\hline & MERRA & 0.42 & 0.24 & 0.41 & 0.59 & 0.31 & 0.41 & 0.98 & -2.25 & 0.96 \\
\hline \multirow[t]{4}{*}{$\mathrm{JF}$} & LIS & 0.38 & 0.14 & 0.70 & 0.56 & 0.23 & 0.70 & 0.94 & -11.06 & 0.72 \\
\hline & NARR & 0.47 & 0.10 & 0.68 & 0.59 & 0.13 & 0.68 & 0.96 & -4.33 & 0.67 \\
\hline & NLDAS & 0.29 & 0.17 & 0.53 & 0.48 & 0.40 & 0.53 & 0.97 & -6.24 & 0.72 \\
\hline & MERRA & 0.28 & 0.12 & 0.66 & 0.56 & 0.34 & 0.66 & 0.97 & -4.62 & 0.71 \\
\hline \multirow[t]{4}{*}{ Mandan } & LIS & 0.44 & 0.12 & 0.57 & 0.40 & 0.17 & 0.57 & 1.02 & 4.43 & 0.68 \\
\hline & NARR & 0.61 & 0.08 & 0.50 & 0.49 & 0.12 & 0.50 & 1.05 & 3.87 & 0.69 \\
\hline & NLDAS & 0.35 & 0.12 & 0.60 & 0.51 & 0.25 & 0.60 & 0.98 & 2.41 & 0.66 \\
\hline & MERRA & 0.36 & 0.10 & 0.66 & 0.39 & 0.25 & 0.66 & 1.07 & 2.81 & 0.63 \\
\hline
\end{tabular}




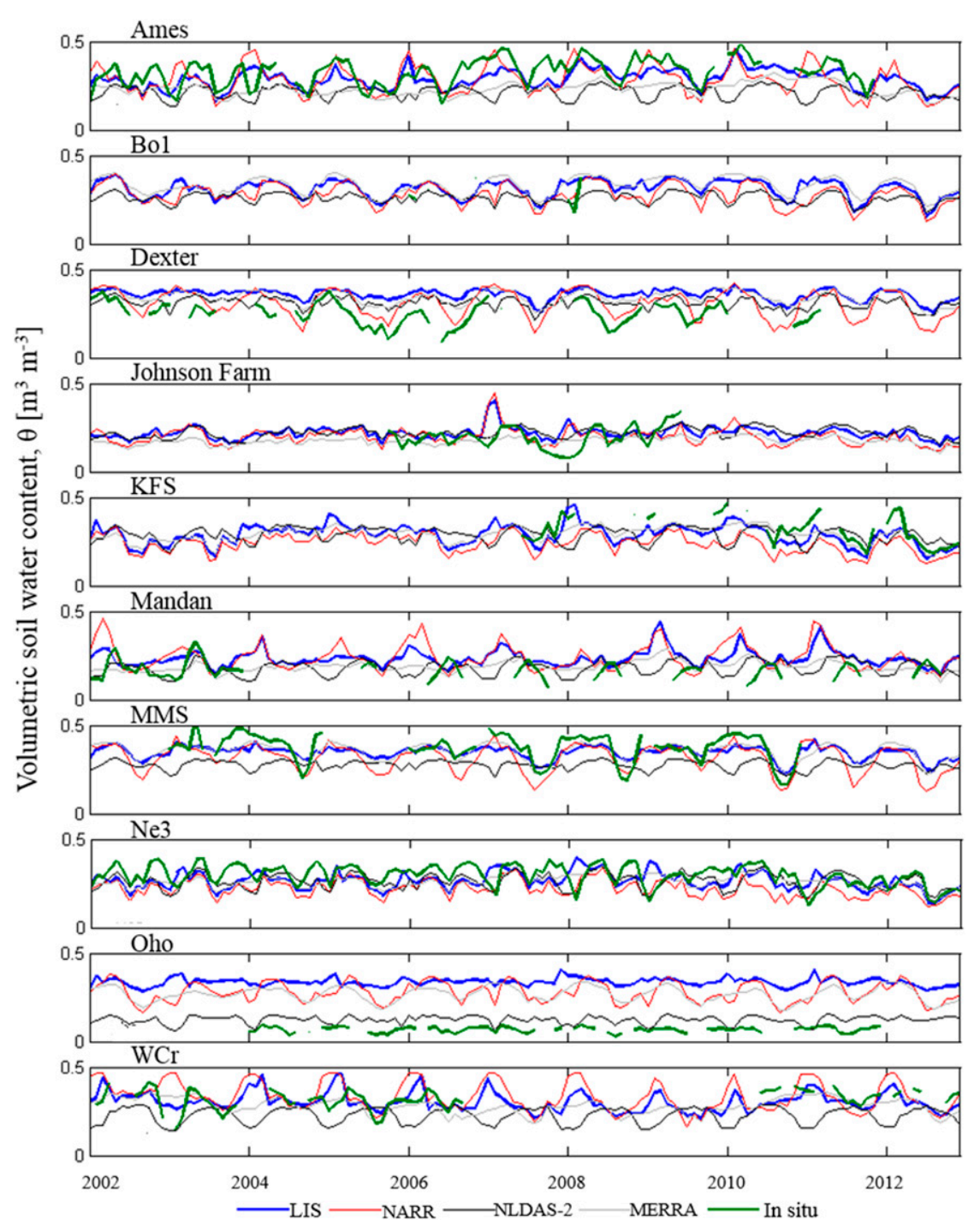

Figure 7. As in Figure 5, but for volumetric soil water content $\theta$.

equipment used at the sites or due to microclimatic differences that are averaged out over the larger grid scale.

Figure 7 shows the time series of volumetric soil water content obtained from the different analyses and in situ observations. Visual inspection suggests an agreement in general temporal variability as well as in the spatial aspects in terms of the different LULC/soil properties; the temporal patterns vary roughly around the median, and no significant mismatches between the different products are noted for most sites. However, it is evident that NLDAS-2 tends to contradict the other datasets in terms of temporal patterns. This is clearly seen for $\mathrm{WCr}$. For the sandy site Oho (second from bottom panel), there is a clear systematic bias between some of the datasets. We attribute this to the hydrometeorological as well as the soil 
Earth Interactions - Volume 21 (2017) • Paper No. 4 • Page 16

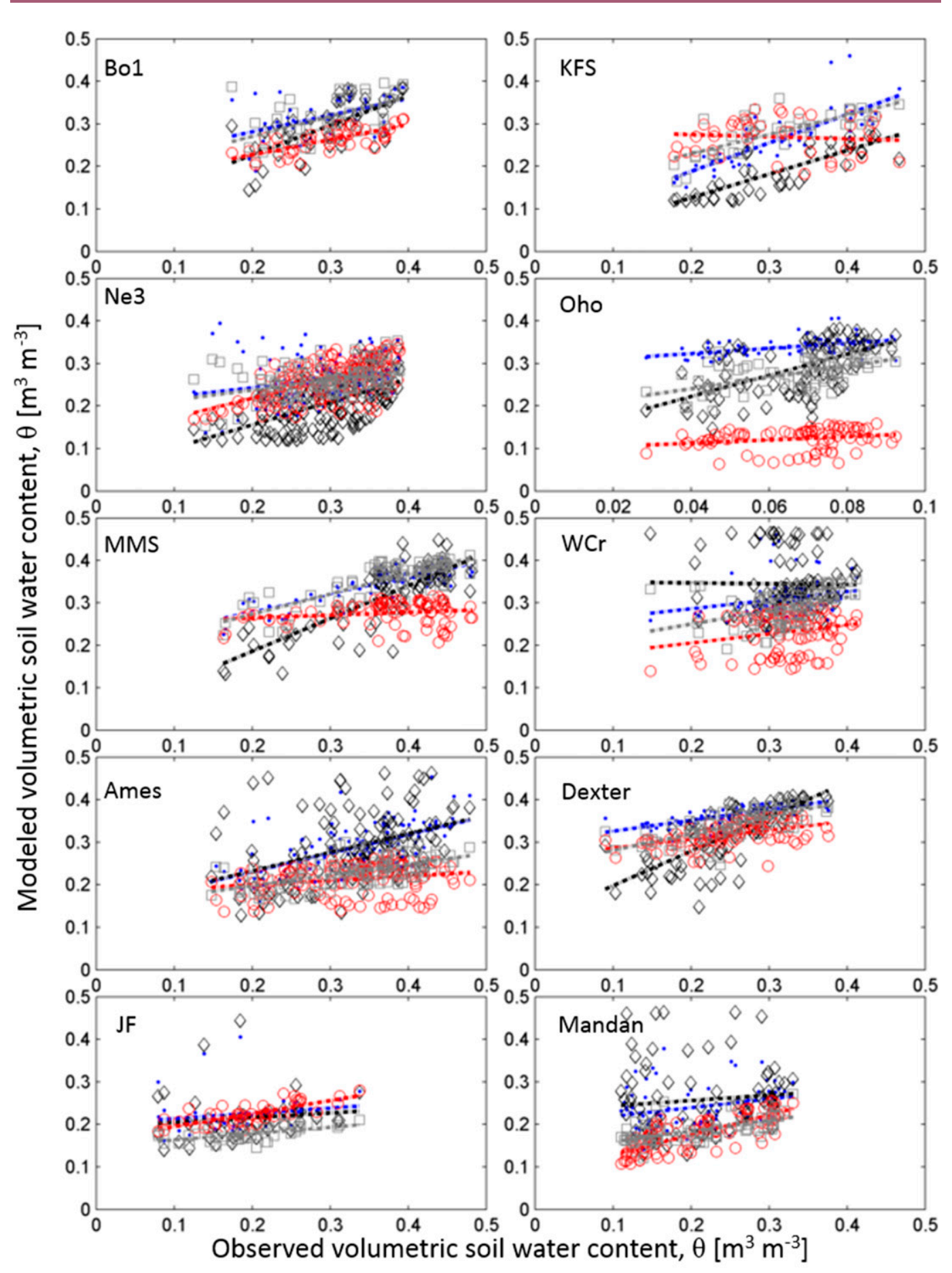

- LIS $\diamond$ NARR $\bigcirc$ NLDAS-2 $\square$ MERRA

Figure 8. As in Figure 6, but for volumetric soil water content $\theta$. 
Earth Interactions - Volume 21 (2017) • Paper No. 4 • Page 17

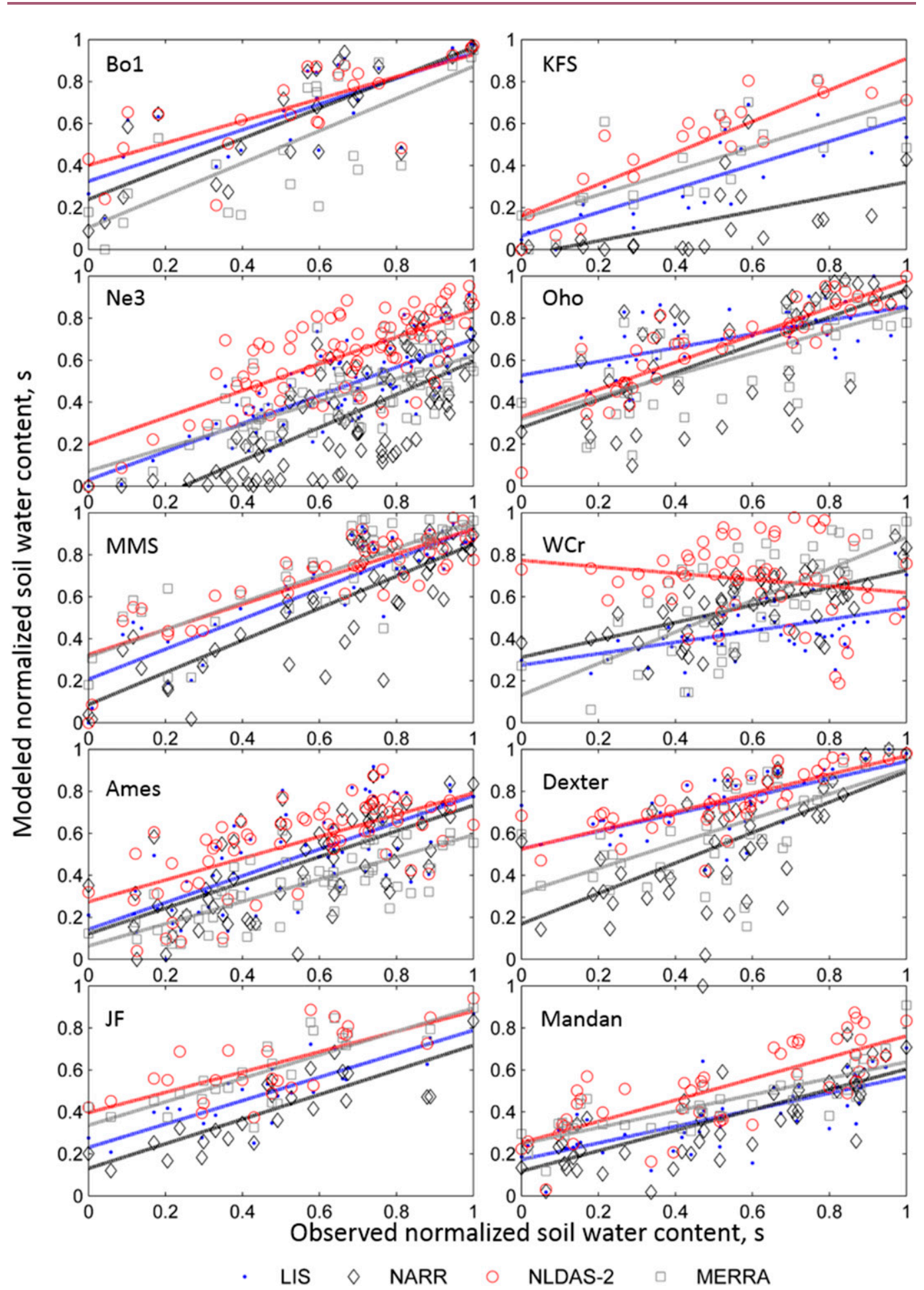

Figure 9. As in Figure 6, but for normalized soil water content $s$. 


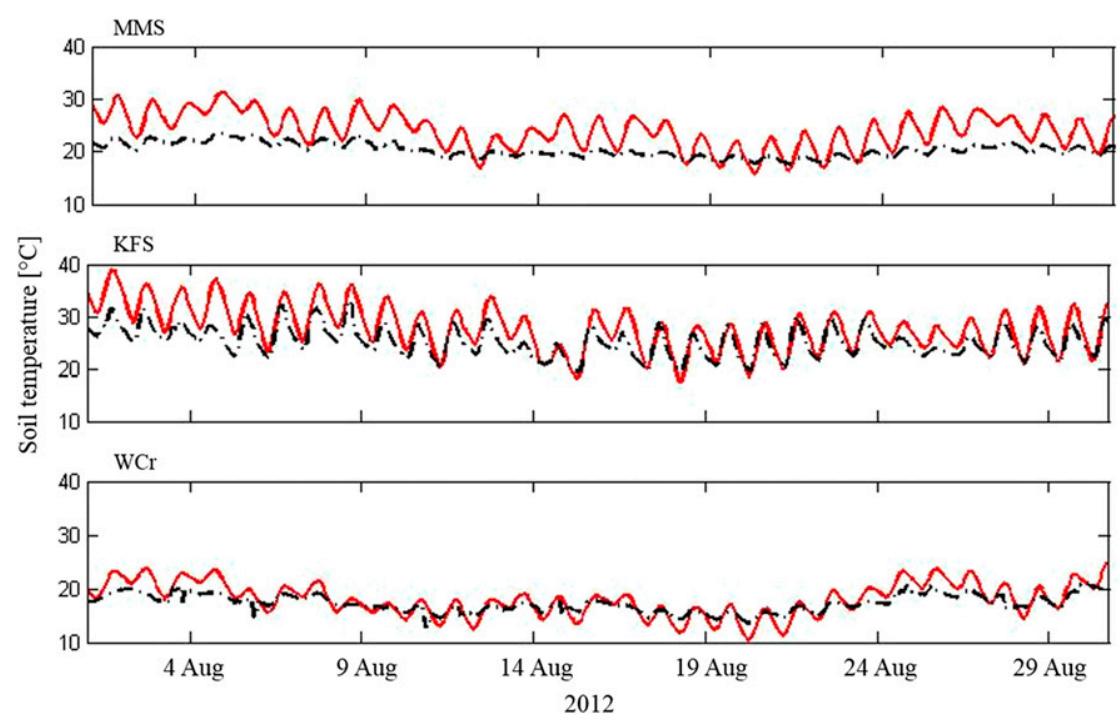

Figure 10. Time series of soil temperature at an hourly time step during August 2012 , corresponding with dry hydroclimatic conditions. LIS data are shown with red solid lines; in situ observations are shown with black dashed lines. Only three sites had data available for the considered time period and at an hourly time step.

hydraulic properties that are assigned to that particular grid. Figure 8 shows the observed growing season volumetric soil water content plotted against the modeled datasets at each site, with linear regressions fitted to each data product. Compared to soil temperature, there is a larger difference between datasets for soil water content, indicating the difficulty of soil water modeling.

To continue making comparisons easier, we normalized the absolute volumetric soil moisture $\theta$ as

$$
s=\frac{\theta-\theta_{\min }}{\theta_{\max }-\theta_{\min }}
$$

where $0 \leq s \leq 1$, and $\theta_{\max }$ and $\theta_{\min }$ are assumed to, over a longer time period, correspond to the saturated and wilting point soil water content, respectively, which both vary by soil texture. Note that only $\theta_{\max }$ and $\theta_{\min }$ from the growing season is used to normalize the soil water content. The results shown in Figure 9 relate to this normalized soil water $s$. The $\theta$ and $s$ values are compared in Table 2 . All of the reanalysis products at different scales are generally able to capture the majority of the hydroclimatic changes well. There are distinct differences between each of the products as well. For instance, LIS tends to fall somewhere between the other products, while NLDAS-2 shows a generally higher relative soil water content than other products when integrated over the top $1 \mathrm{~m}$ (see supplemental information: Figure S1, Movies 1 and 2). NLDAS-2 also shows an opposite trajectory compared to the other products for WCr (Figures 7, 9). NARR shows a distinct bias to be underrepresenting soil moisture in some locations, such as KFS and Ne3. MERRA 


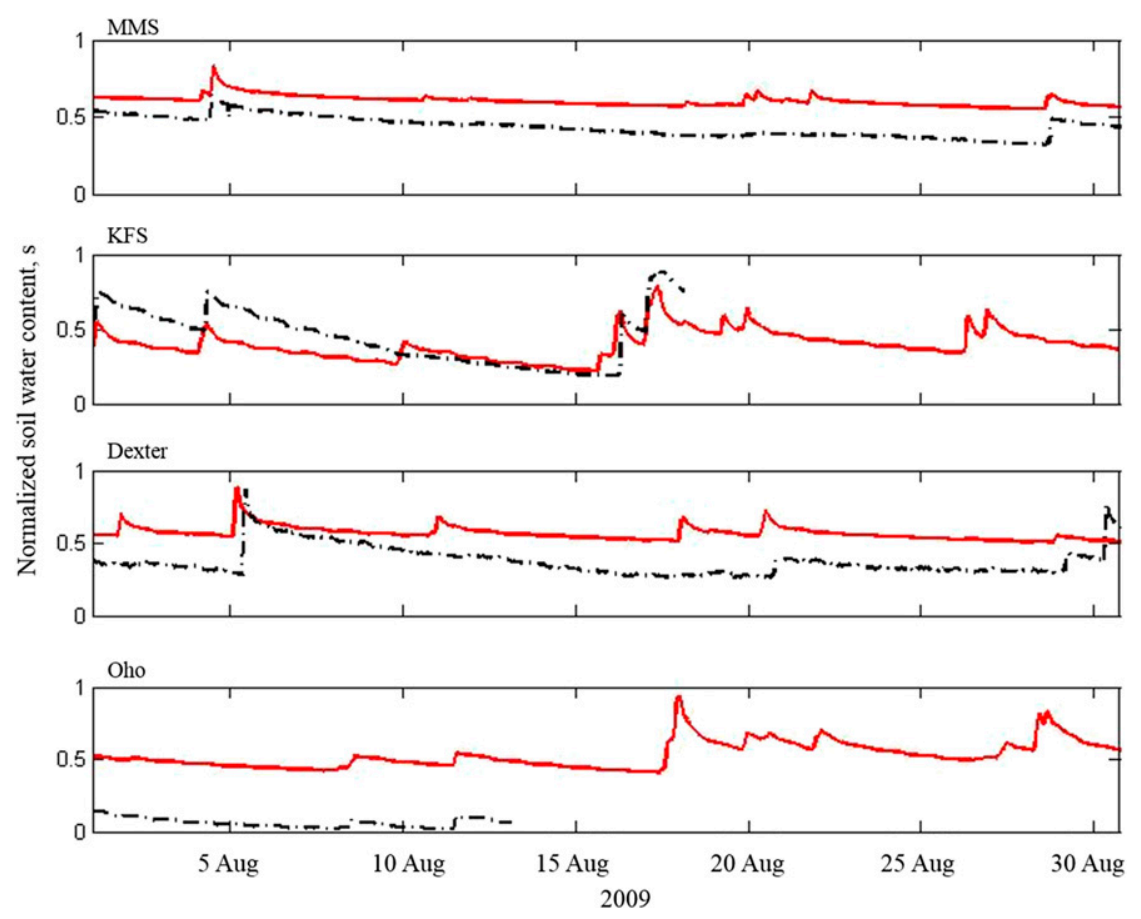

Figure 11. Time series of normalized soil water content $s$ at an hourly time step during August 2009, corresponding with normal hydroclimatic conditions. LIS data are shown with red solid lines; in situ observations are shown with black dashed lines. Only four sites had data available for at least part of the considered time period and at an hourly time step.

is generally located in between the other products. Clearly, the analysis cannot be used to evaluate which product is better, but we can at this point conclude that there is strong agreement in many regards between the datasets, but individual products will have their own climatology for the region. This information is important to consider when choosing and using these products in various applications.

The data were also compared with observations at a shorter, hourly time scale. The hourly time-scale data were compared (Figures 10-14) for four different attributes related to, for the region, relatively normal (August 2009), wet (June 2010), hot (July 2011), and dry (August 2012) conditions based on NOAA's regional temperature and precipitation maps (http://www.ncdc.noaa.gov/tempand-precip/us-maps/). The regional temperature and precipitation tendencies, based on the twentieth-century normal, for these months were as follows: below normal precipitation and temperatures (August 2009), higher than normal temperatures and precipitation (June 2010), higher than normal temperatures with higher than normal precipitation in the northwestern and less than normal precipitation in the southeastern parts of the study region (July 2011), and normal to slightly less than normal precipitation and normal temperatures (August 2012). It is worth mentioning that July 2012 was much drier and warmer than normal, contributing to the August drought conditions. On the finer temporal scale, LIS 

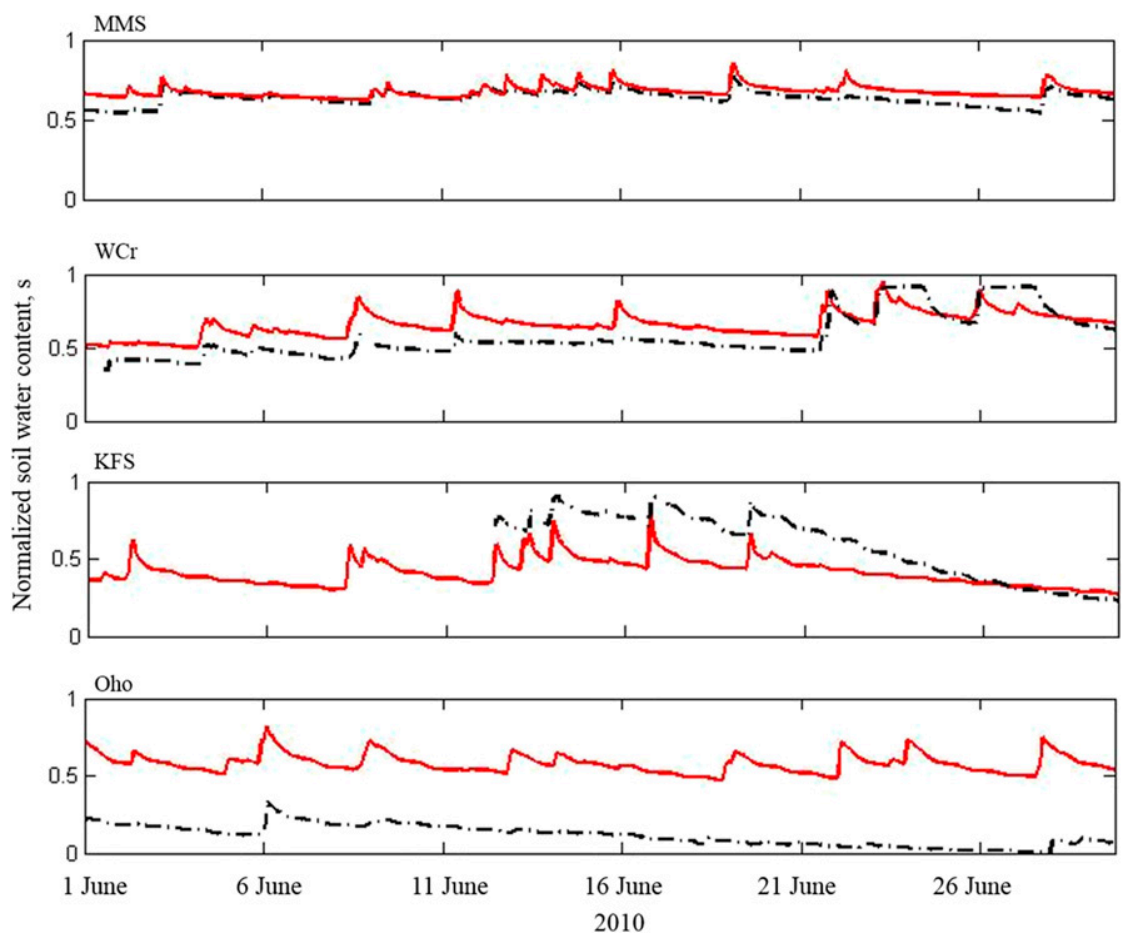

Figure 12. As in Figure 11, but for June 2010, corresponding to abnormally wet hydroclimatic conditions.

tends to overestimate the soil temperature (Figure 10). In addition, the periodic fluctuations are generally more dampened in the in situ observations compared to the LIS data. Again, the match in temporal evolution of $s$ between observed data and the LDAS fields is notable, but it is also seen that in a few locations, despite the normalization of soil moisture, there can still be a strong mismatch in magnitude between the observations and those produced by the LDAS. The features that are considered are as follows: Are these models on a larger scale able to capture the finer-scale attributes that emerge into the analysis? To review this feature, one of the notable hydroclimatic aspects available from the data period is the 2012 drought that affected the U.S. Corn Belt. The soil water variability that emerges from the different products are compared for the normal, wet, hot, and dry conditions referred to in Figures 11-14. The data products were also compared spatially for the same hydroclimatic conditions (Figure 15). All data products show similar patterns and are generally able to capture drought occurrences. NLDAS-2 tends to be wetter, while NARR tends to be drier than other reanalyses. In August 2012, an area of anomalous soil wetness conditions can be observed in the eastern part of the domain, east of Lake Huron and north of Lake Erie. This anomaly is present in LIS, NARR, and NLDAS-2 and is identified as being tied to erroneously high simulated precipitation in that region throughout 2012. To further explore the ability of the LIS product to capture drought occurrence, a simple proxy soil moisture drought index is adapted based 


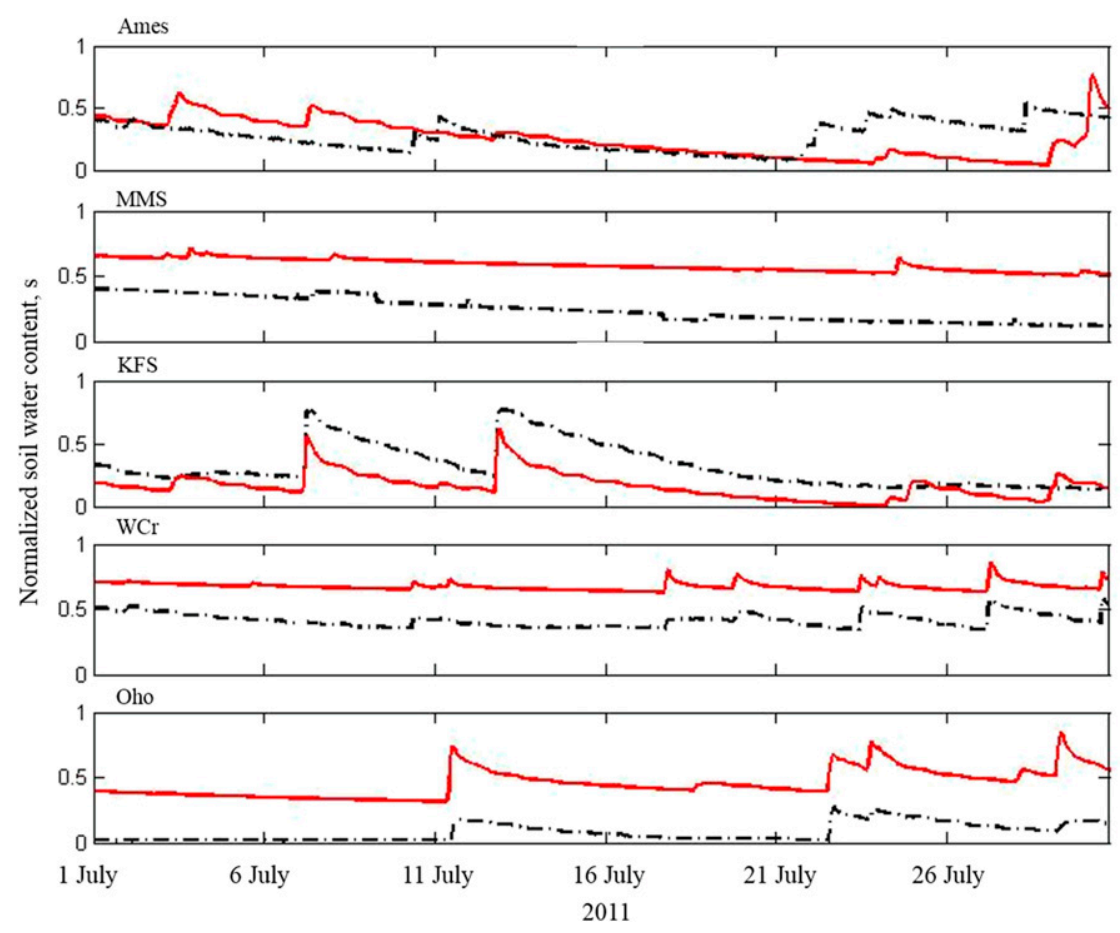

Figure 13. As in Figure 11, but for July 2011 , corresponding to abnormally warm climatic conditions. Here, five sites had in situ data available for the period of interest.

on the method in Xia et al. (2014a,b) and (Case et al. 2015), where the USDM drought categories are related to percentile thresholds of normalized soil water content. The thresholds are set as follows: D0 (abnormally dry; percentile $\geq 30 \%$ ), D1 (moderate drought; percentile $\geq 20 \%$ ), D2 (severe drought; percentile $\geq 10 \%$ ), D3 (extreme drought; percentile $\geq 5 \%$ ), and D4 (exceptional drought; percentile $\geq 2 \%$ ). Figure 16 shows the same information as Figure 15 but with only areas of $s \geq 0.2$, corresponding to moderate drought. As can be noted, the NLDAS-2 has relatively patchy drought occurrences during the 2012 drought and is not able to capture the extent of the drought, while NARR is overestimating the drought. LIS and MERRA show similar patterns, with LIS being able to capture some of the more finescale features.

Considering the complexity of the hydrodynamic features within the models, this apparent difference in agreement between soil moisture and soil temperature is not surprising. Again, for soil water content there was a strong soil textural bias in terms of the differences that can be noted between the different reanalysis products. For soil temperature, no such systematic bias was noted.

Additionally, the LIS generated evapotranspiration (ET) for the 4 months identified to correspond to normal, unusually wet, warm, and dry conditions is compared with the MODIS global evapotranspiration product (MOD16; Mu et al. 2007, 2011). The monthly MODIS ET product at 1-km spatial resolution was used. While the MOD16 ET product is based on satellite observations, it is derived 


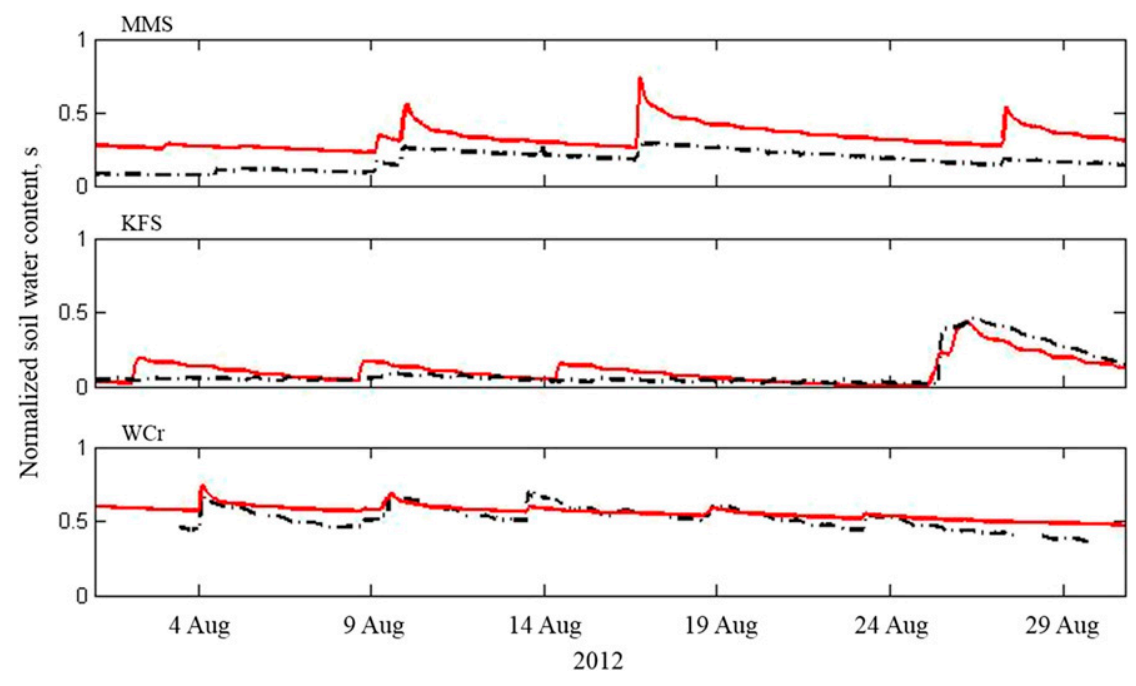

Figure 14. As in Figure 11, but for August 2012, corresponding to abnormally dry hydroclimatic conditions. Here, three sites had in situ data available for at least part of the period of interest.

through a Penman-Monteith-based algorithm (Mu et al. 2007, 2011). Figure 17 shows that the LIS ET is consistently higher than MODIS. During the anomalously warm month of July 2011, LIS ET is considerably higher than the MODIS product, particularly in the center of the domain. While the reason for this bias is not fully clear, Miller et al. (2006) showed that the choice of GVF product as input to the Noah LSM significantly affects modeled transpiration rates, particularly in summer.

\section{The role of stakeholders}

The creation of this hydroclimatic dataset was driven by a need for climatebased decision support tools within the agronomic community in the U.S. Midwest. At the beginning of the project, $\mathrm{U} 2 \mathrm{U}$ team members initiated a dialogue, through surveys, with stakeholders, including farmers, public and private agricultural advisors, and extension educators (Prokopy et al. 2017). Stakeholders were asked about their beliefs regarding climate change and attitudes toward climate adaptation and mitigation (Arbuckle et al. 2013). Agricultural advisors were also asked whether weather and/or climate information is used when giving advice to farmers and what type of weather and/or climate-related decision support resources they use (Prokopy et al. 2013). Results from the surveys and related studies revealed that weather and climate information for agriculture is underutilized, which could be explained by factors such as perceptions of low forecast accuracy and greater concern with other, nonweather, risks (Mase and Prokopy 2014). Based on the feedback from stakeholders, the U2U team developed a number of weather- and climate-related agricultural decision support tools (DSTs) including a climate pattern viewer, a growing degree-day tool, a nitrogen application tool, and an 
Earth Interactions - Volume 21 (2017) • Paper No. 4 • Page 23

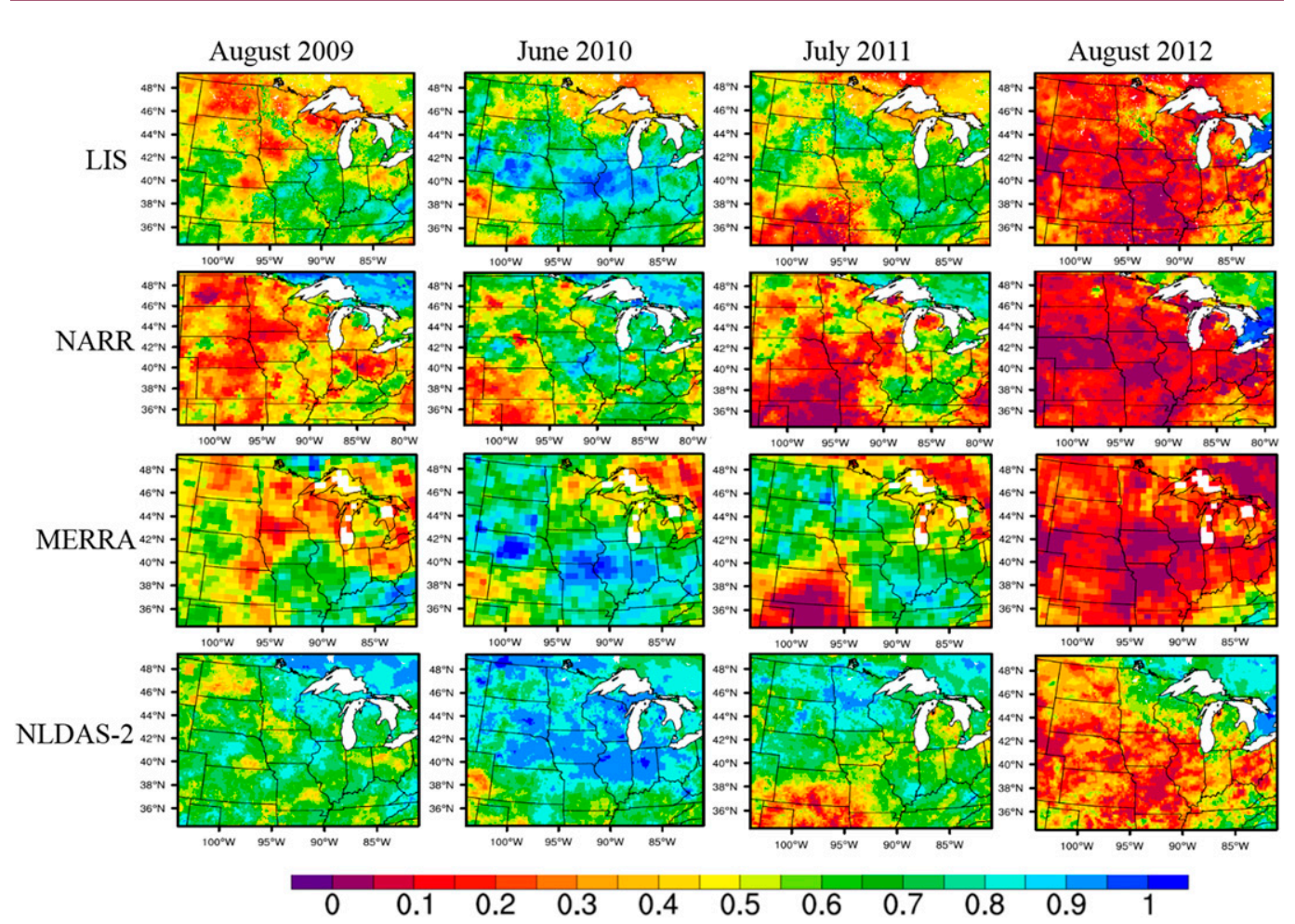

Figure 15. Spatial comparison of normalized soil water content $s$ for (left to right) August 2009, June 2010, July 2011, and August 2012 and (top to bottom) LIS, NARR, MERRA, and NLDAS-2.

irrigation tool (www.agclimate4u.org; Angel et al. 2017; Gramig et al. 2017; Prokopy et al. 2017). In the development of the decision support tools, we identified gaps in the observational data record for key variables needed as input to these DSTs. As discussed in section 1, other LDAS and reanalysis products are available but at spatial resolutions too coarse for field-scale applications and integration with crop models. While the dataset is not intended for direct use by stakeholders, the data produced are important for the development of the DSTs requested by the Midwestern agronomic community, as input to crop models and for regional hydrologic assessments.

\section{Conclusions and fulture directions}

Some of the lessons learned include that it is incredibly difficult to develop a synthesis for multiple datasets, and it is not a simple task to try to ascertain the credibility of different products. Even comparing observations with gridded datasets is a nontrivial assessment, and that has its own uncertainties that need to be considered (Director and Bornn 2015). We find that the model is grossly overestimating soil water content during frozen conditions and hence focus our efforts on the period of greater interest to the agricultural community: the growing season. While the LIS dataset and the coarser reanalysis products generally compare well 
Earth Interactions - Volume 21 (2017) • Paper No. 4 • Page 24

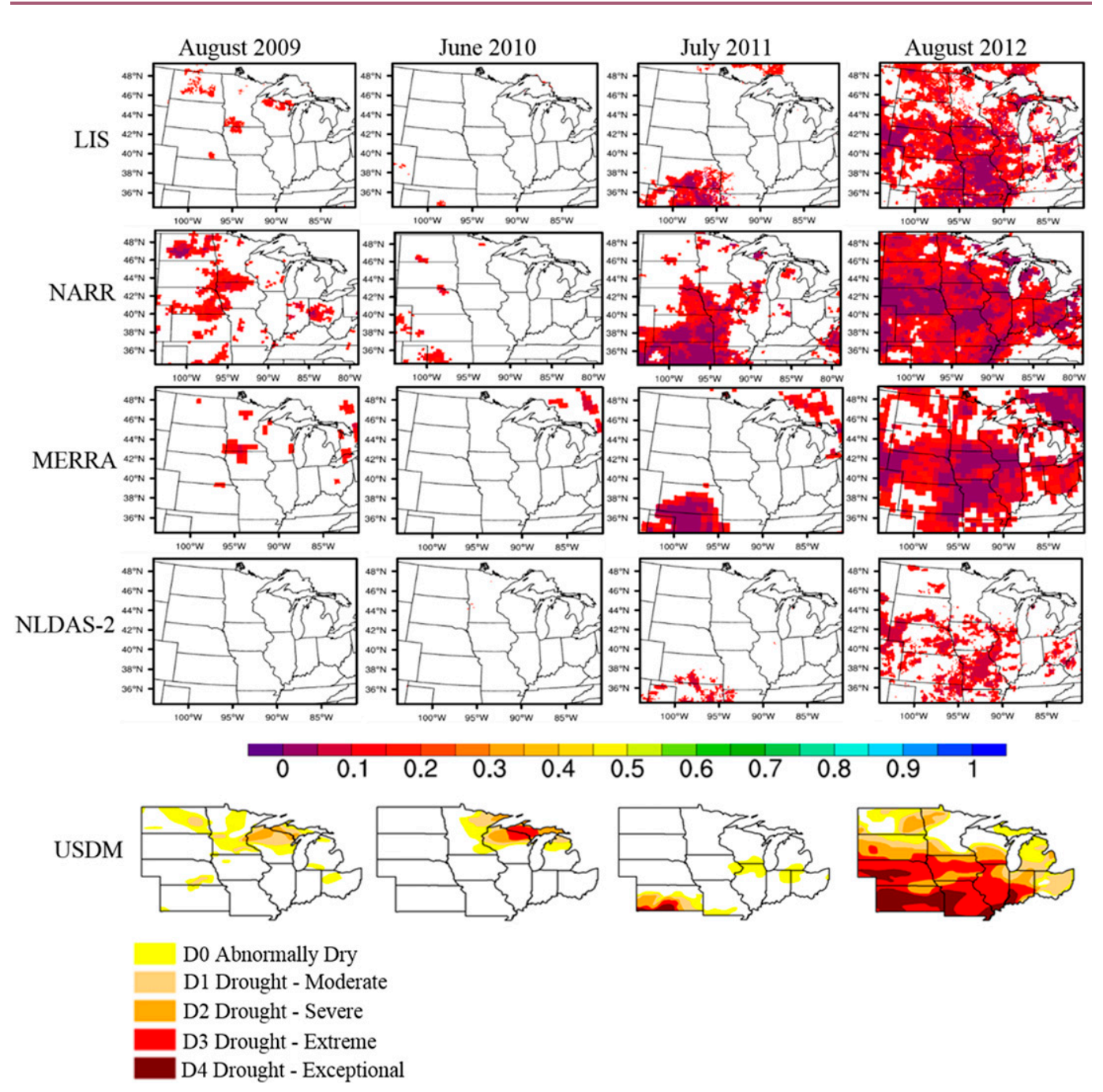

Figure 16. As in Figure 12, but showing only $s \leq 0.2$, corresponding to USDM D1-D4. Also shown is the USDM map for the domain from the middle of each represented month.

with in situ soil water storage and soil temperature observations in terms of temporal patterns at the monthly time scale, there are also discrepancies in magnitudes and in some cases trajectories. Because of the differences in spatial scale, these data products are not well suited for point-scale predictions of soil water content as it tends to be largely affected by local soil properties. In addition, there are issues with a long spinup time for soil water content in the deepest soil layer, and those data should be used with caution. However, the data products do reproduce regional-scale spatial patterns of soil water well. Spatially, LIS is able to capture features at a finer scale than the coarser analyses, which is useful for more precise information for agricultural applications. The spatial soil moisture variability that emerges during four hydroclimatic states (normal, wet, dry, and hot) is compared 
Earth Interactions - Volume 21 (2017) • Paper No. 4 • Page 25

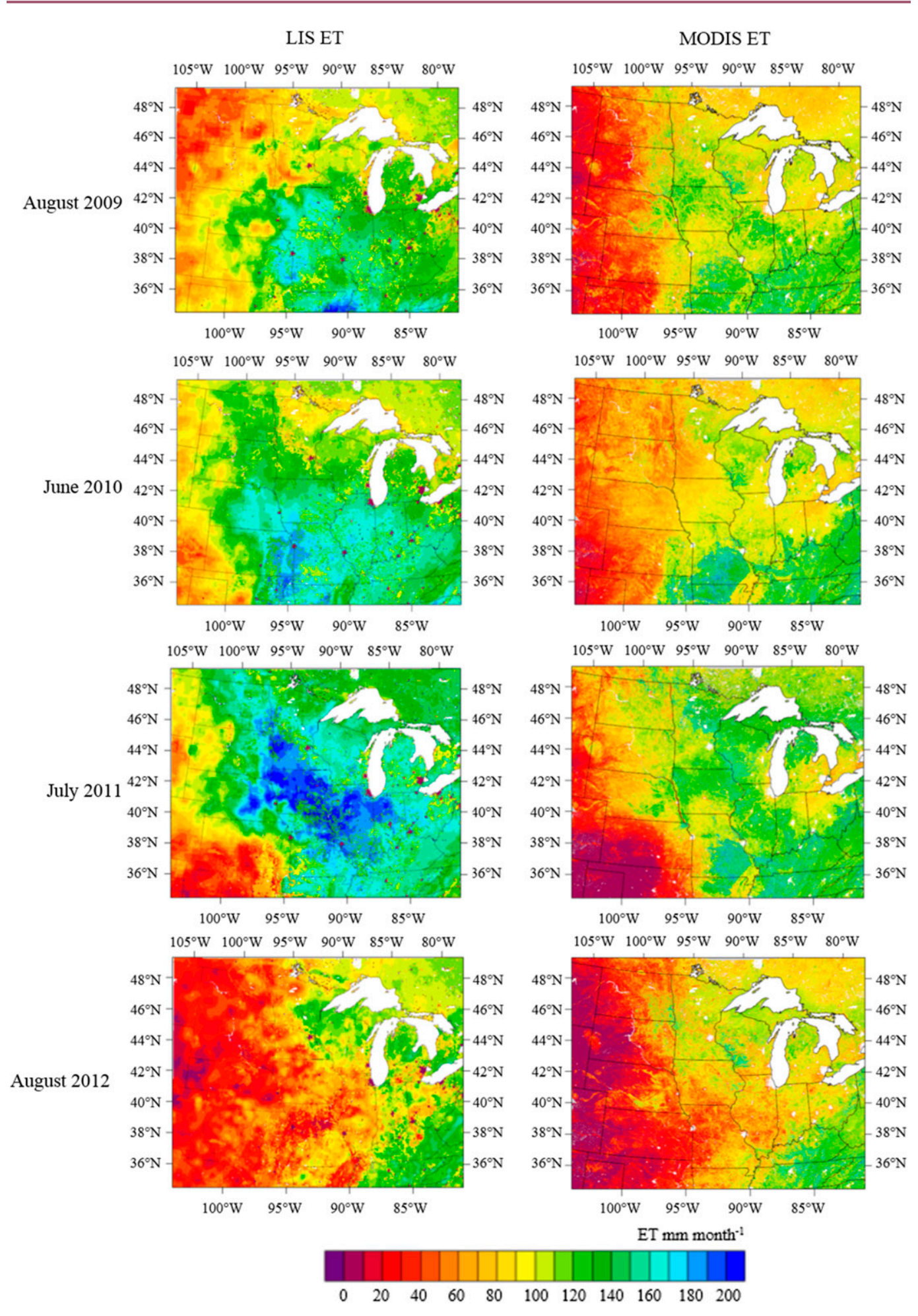

Figure 17. Comparison of (left) LIS simulated total ET and (right) MODIS-observed/ derived ET for (top to bottom) August 2009, June 2010, July 2011, and August 2012. 
Earth Interactions - Volume 21 (2017) • Paper No. 4 • Page 26

with the U.S. Drought Monitor for a corresponding point in time revealing a good correspondence of spatial patterns. LIS-generated evapotranspiration is compared with the remotely sensed MODIS ET product for the four hydroclimatic states above. LIS ET is consistently higher than MODIS ET, particularly during anomalously hot conditions. In general, LIS is able to capture features at a finer scale than the coarser analyses, which makes this new dataset a better candidate for regional hydroclimatic and crop climate studies.

Additional analysis with the new LIS hydroclimatic dataset are currently underway and will be reported in follow-up cases and studies that are provided in companion studies. A brief summary includes work showing that when these data are used in a crop model, the results actually can be improved (Liu et al. 2015). Other examples include a study of the relationships that emerge between air temperature and soil temperature. Work is also underway to use this information for crop growing field work, for conducting regional crop model analyses, and in a complimentary effort where future climate projections using the North American Regional Climate Change Project (NARCCAP; Mearns et al. 2009) and/or phase 5 of the Coupled Model Intercomparison Project (CMIP5) forcing (Taylor et al. 2012) is used to determine how the regional hydroclimatology could be changing.

The data production, maintenance, and management issue is a considerable engineering task as well as making visualizations and data available to the larger community. The data interface at $4 \mathrm{~km}$ was a judicious choice based on data input, but it also appears to be a feasible interface between the field-scale and regional-scale assessment and analysis. The initial crop model results executed within the U2U group based on these data have shown a positive impact associated with the features that are emerging from the analysis. The higher-resolution product also seems to aid in drought assessment, and efforts are currently underway to communicate these findings to the broader extension and outreach community. The role of land-use/ land-cover change has not been considered in our current assessment, and the stationarity of the land cover has been one of the prominent features that need to be pursued in a future study. These data will be undergoing further massaging and synthesis, but at this point they are becoming available to the community. With the advent of additional remotely sensed products such as SMAP, the utility of such gridded high-resolution soil moisture products for agroclimatic applications and gridded climatic yield assessments will continue further, assisting the scientific community in their ability to provide resiliency approaches for hydrological extremes such as droughts.

Acknowledgments. This research is part of "Useful to Usable (U2U): Transforming Climate Variability and Change Information for Cereal Crop Producers" and is supported by Agriculture and Food Research Initiative Competitive Grant 2011-68002-30220 from the USDA National Institute of Food and Agriculture. Partial funding for EMJ and PSCR was provided by the Lee A. Rieth endowment in the Lyles School of Civil Engineering at Purdue University. The PI's for the following AmeriFlux sites are acknowledged for their data records: US-Bo1, US-KFS, US-MMS, US-Oho, US-Ne3, and US-WCr. In addition, funding for AmeriFlux data resources was provided by the U.S. Department of Energy's Office of Science. MERRA data used in this study have been provided by the Global Modeling and Assimilation Office (GMAO) at NASA Goddard Space Flight Center through the NASA GES DISC online archive. The authors report no conflicts of interest. 
Earth Interactions V Volume 21 (2017) • Paper No. 4 • Page 27

Table A1. List of all available LIS output variables. All variables are at 4-km grid spacing and a daily time step.

\begin{tabular}{lll}
\hline \multicolumn{1}{c}{ Variable } & \multicolumn{1}{c}{ Description } & Units \\
\hline Energy balance components & Net shortwave radiation & \\
SWnet & Net longwave radiation & $\mathrm{W} \mathrm{m}^{-2}$ \\
LWnet & Latent heat flux & $\mathrm{W} \mathrm{m}^{-2}$ \\
Qle & Sensible heat flux & $\mathrm{W} \mathrm{m}^{-2}$ \\
Qh & Ground heat flux & $\mathrm{W} \mathrm{m}^{-2}$ \\
Qg & Bowen ratio & $\mathrm{W} \mathrm{m}^{-2}$ \\
BR & Evaporative fraction & - \\
EF & & - \\
Water balance components & Snowfall rate & \\
Snowf & Rainfall rate & $\mathrm{kg} \mathrm{m}^{-2} \mathrm{~s}^{-1}$ \\
Rainf & Total precipitation rate & $\mathrm{kg} \mathrm{m}^{-2} \mathrm{~s}^{-1}$ \\
TotalPrecip & Total evapotranspiration rate & $\mathrm{kg} \mathrm{m}^{-2} \mathrm{~s}^{-1}$ \\
Evap & Surface runoff & $\mathrm{kg} \mathrm{m}^{-2} \mathrm{~s}^{-1}$ \\
Qs & Subsurface runoff & $\mathrm{kg} \mathrm{m}^{-2} \mathrm{~s}^{-1}$ \\
Qsb & Change in column soil moisture & $\mathrm{kg} \mathrm{m}^{-2} \mathrm{~s}^{-1}$ \\
DelSoilMoist & & $\mathrm{kg} \mathrm{m}^{-2}$ \\
Evapotranspiration components & Vegetation transpiration & \\
Tveg & Bare soil evaporation & $\mathrm{kg} \mathrm{m}^{-2} \mathrm{~s}^{-1}$ \\
Esoil & Root zone soil moisture & $\mathrm{kg} \mathrm{m}^{-2} \mathrm{~s}^{-1}$ \\
RootMoist & Total canopy water storage & $\mathrm{m}^{3} \mathrm{~m}^{-3}$ \\
CanopInt & Canopy conductance & $\mathrm{kg} \mathrm{m}^{-2} \mathrm{~s}^{-1}$ \\
Ccond & & $\mathrm{m} \mathrm{s}^{-1}$ \\
Surface state variables & Snow cover fraction & \\
SnowCover & Depth of snow layer & - \\
SnowDepth & Average layer soil moisture & $\mathrm{m}^{-1}$ \\
Subsurface state variables & Average layer soil temperature & $\mathrm{K} \mathrm{m}^{3} \mathrm{~m}^{-3}$ \\
SoilTemp & & \\
\hline & &
\end{tabular}

The dataset described in this study is archived and distributed via the U2U data portal (www.agclimate4u.org) and will be available to access publicly.

\section{APPENDIX}

\section{LIS Outpult Variables}

\section{Available LIS output variables are given in Table A1.}

\section{References}

Angel, J. R., M. Widhalm, D. Todey, R. Massey, and L. Biehl, 2017: The U2U corn growing degree day tool: Tracking corn growth across the US Corn Belt. Climate Risk Manage., 15, 73-81, doi:10.1016/j.crm.2016.10.002.

Arbuckle, J. G., and Coauthors, 2013: Climate change beliefs, concerns, and attitudes toward adaptation and mitigation among farmers in the Midwestern United States. Climatic Change, 117, 943-950, doi:10.1007/s10584-013-0707-6.

Baldwin, M. E., and K. E. Mitchell, 1996: The NCEP hourly multi-sensor U.S. precipitation analysis. Preprints, 15th Conf. on Weather Analysis and Forecasting/11th Conf. Numerical Weather Prediction, Norfolk, VA, Amer. Meteor. Soc., J95-J96. 


\section{Earth Interactions - Volume 21 (2017) • Paper No. 4 • Page 28}

Bollero, A., G. Bullock, and S. E. Hollinger, 1996: Soil temperature and planting date effects on corn yield, leaf area, and plant development. Agron. J., 88, 385-390, doi:10.2134/ agronj1996.00021962008800030005x.

Case, J. L., B. T. Zavodsky, and J. E. Bell, 2015: Development of a 30-year soil moisture climatology for situational awareness and public health applications. 29th Conf. on Hydrology, Phoenix, AZ, Amer. Meteor. Soc., 4.4. [Available online at https://ams.confex.com/ams/ 95Annual/webprogram/Paper267173.html.]

Challinor, A. J., J. Watson, D. B. Lobell, S. M. Howden, D. R. Smith, and N. Chhetri, 2014: A metaanalysis of crop yield under climate change and adaptation. Nat. Climate Change, 4, 287291, doi:10.1038/nclimate2153.

Chaney, N. W., J. K. Roundy, J. E. Herrera-Estrada, and E. F. Wood, 2015: High-resolution modeling of the spatial heterogeneity of soil moisture: Applications in network design. Water Resour. Res., 51, 619-638, doi:10.1002/2013WR014964.

Chen, F., and J. Dudhia, 2001: Coupling an advanced land surface-hydrology model with the Penn State-NCAR MM5 modeling system. Part I: Model implementation and sensitivity. Mon. Wea. Rev., 129, 569-585, doi:10.1175/1520-0493(2001)129<0569: CAALSH $>2.0 . \mathrm{CO} ; 2$.

— Resolution Land Data Assimilation System. J. Appl. Meteor. Climatol., 46, 694-713, doi:10.1175/JAM2463.1.

Cook, B. D., and Coauthors, 2004: Carbon exchange and venting anomalies in an upland deciduous forest in northern Wisconsin, USA. Agric. For. Meteor., 126, 271-295, doi:10.1016/j.agrformet.2004.06.008.

Cosby, B. J., G. M. Hornberger, R. B. Clapp, and T. R. Ginn, 1984: A statistical exploration of the relationships of soil moisture characteristics to the physical properties of soils. Water Resour. Res., 20, 682-690, doi:10.1029/WR020i006p00682.

Director, H., and L. Bornn, 2015: Connecting point-level and gridded moments in the analysis of climate data. J. Climate, 28, 3496-3510, doi:10.1175/JCLI-D-14-00571.1.

Ek, M. B., 2003: Implementation of Noah land surface model advances in the National Centers for Environmental Prediction operational mesoscale Eta model. J. Geophys. Res., 108, 8851, doi:10.1029/2002JD003296.

Entekhabi, B. D., and Coauthors, 2010: The Soil Moisture Active Passive (SMAP) mission. Proc. IEEE, 98, 704-716, doi:10.1109/JPROC.2010.2043918.

Gramig, B. M., R. Massey, and S. Do Yun, 2017: Nitrogen application decision-making under climate risk in the U.S. Corn Belt. Climate Risk Manage., 15, 82-89, doi:10.1016/ j.crm.2016.09.001.

Hansen, M. C., R. S. DeFries, J. R. G. Townshend, and R. Sohlberg, 2000: Global land cover classification at $1 \mathrm{~km}$ spatial resolution using a classification tree approach. Int. J. Remote Sens., 21, 1331-1364, doi:10.1080/014311600210209.

Hollinger, S. E., and S. A. Isard, 1994: A soil moisture climatology of Illinois. J. Climate, 7, 822 833, doi:10.1175/1520-0442(1994)007<0822:ASMCOI>2.0.CO;2.

Houser, P. R., 2003: Land data assimilation systems. Data Assimilation for the Earth System, R. Swinbank, V. Shutyaev, and W. A. Lahoz, Eds., Kluwer Academic Publishers, 345360.

Hu, Q., and S. Feng, 2004: A role of the soil enthalpy in land memory. J. Climate, 17, 3633-3643, doi:10.1175/1520-0442(2004)017<3633:AROTSE > 2.0.CO;2.

Ines, A. V. M., N. N. Das, J. W. Hansen, and E. G. Njoku, 2013: Assimilation of remotely sensed soil moisture and vegetation with a crop simulation model for maize yield prediction. Remote Sens. Environ., 138, 149-164, doi:10.1016/j.rse.2013.07.018.

Jacquemin, B., and J. Noilhan, 1990: Sensitivity study and validation of a land surface parameterization using the HAPEX-MOBILHY data set. Boundary-Layer Meteor., 52, 93-134, doi:10.1007/BF00123180. 


\section{Earth Interactions • Volume 21 (2017) • Paper No. 4 • Page 29}

Kerr, Y. H., and Coauthors, 2010: The SMOS mission: New tool for monitoring key elements of the global water cycle. Proc. IEEE, 98, 666-687, doi:10.1109/JPROC.2010.2043032.

Kumar, S. V., and Coauthors, 2006: Land information system: An interoperable framework for high resolution land surface modeling. Environ. Modell. Software, 21, 1402-1415, doi:10.1016/j.envsoft.2005.07.004.

— - R. H. Reichle, C. D. Peters-Lidard, R. D. Koster, X. Zhan, W. T. Crow, J. B. Eylander, and P. R. Houser, 2008: A land surface data assimilation framework using the land information system: Description and applications. Adv. Water Resour., 31, 1419-1432, doi:10.1016/j.advwatres.2008.01.013.

Liu, X., J. Andresen, H. Yang, and D. Niyogi, 2015: Calibration and validation of the hybrid-maize crop model for regional analysis and application over the U.S. Corn Belt. Earth Interact., 19, doi:10.1175/EI-D-15-0005.1.

— E. Jacobs, A. Kumar, L. Biehl, J. Andresen, and D. Niyogi, 2017: The Purdue Agro-climatic (PAC) dataset for the U.S. Corn Belt: Development and initial results. Climate Risk Manage., 15, 61-72, doi:10.1016/j.crm.2016.10.005.

Livneh, B., Y. Xia, K. E. Mitchell, M. B. Ek, and D. P. Lettenmaier, 2010: Noah LSM snow model diagnostics and enhancements. J. Hydrometeor, 11, 721-738, doi:10.1175/ 2009JHM1174.1.

— , E. A. Rosenberg, C. Lin, B. Nijssen, V. Mishra, K. M. Andreadis, E. P. Maurer, and D. P. Lettenmaier, 2013: A long-term hydrologically based dataset of land surface fluxes and states for the conterminous United States: Update and extensions. J. Climate, 26, 9384-9392, doi:10.1175/JCLI-D-12-00508.1.

Lobell, D. B., M. J. Roberts, W. Schlenker, N. Braun, B. B. Little, R. M. Rejesus, and G. L. Hammer, 2014: Greater sensitivity to drought accompanies maize yield increase in the U.S. Midwest. Science, 344, 516-519, doi:10.1126/science.1251423.

Mahrt, L., and M. Ek, 1984: The influence of atmospheric stability on potential evaporation. J. Climate Appl. Meteor., 23, 222-234, doi:10.1175/1520-0450(1984)023<0222: TIOASO $>2.0 . \mathrm{CO} ; 2$.

— doi:10.1007/BF00119116.

Mase, A. S., and L. S. Prokopy, 2014: Unrealized potential: A review of perceptions and use of weather and climate information in agricultural decision making. Wea. Climate Soc., 6, 4761, doi:10.1175/WCAS-D-12-00062.1.

Mearns, L. O., W. Gutowski, R. Jones, R. Leung, S. McGinnis, A. Nunes, and Y. Qian, 2009: A regional climate change assessment program for North America. Eos, Trans. Amer. Geophys. Union, 90, 311-311, doi:10.1029/2009EO360002.

Mesinger, F., and Coauthors, 2006: North American Regional Reanalysis. Bull. Amer. Meteor. Soc., 87, 343-360, doi:10.1175/BAMS-87-3-343.

Miller, J., M. Barlage, X. Zeng, H. Wei, K. Mitchell, and D. Tarpley, 2006: Sensitivity of the NCEP/ Noah land surface model to the MODIS green vegetation fraction data set. Geophys. Res. Lett., 33, L13404, doi:10.1029/2006GL026636.

Mu, Q., F. A. Heinsch, M. Zhao, and S. W. Running, 2007: Development of a global evapotranspiration algorithm based on MODIS and global meteorology data. Remote Sens. Environ., 106, 285-304, doi:10.1016/j.rse.2006.07.007.

— M. Zhao, and S. W. Running, 2011: Improvements to a MODIS global terrestrial evapotranspiration algorithm. Remote Sens. Environ., 115, 1781-1800, doi:10.1016/j.rse.2011.02.019.

Noilhan, J., and S. Planton, 1989: A simple parameterization of land surface processes for meteorological models. Mon. Wea. Rev., 117, 536-549, doi:10.1175/1520-0493(1989)117<0536: ASPOLS $>2.0 . \mathrm{CO} ; 2$.

Ochsner, T. E., and Coauthors, 2013: State of the art in large-scale soil moisture monitoring. Soil. Sci. Soc. Amer. J., 77, 1888-1919, doi:10.2136/sssaj2013.03.0093. 


\section{Earth Interactions • Volume 21 (2017) • Paper No. 4 • Page 30}

Pan, H.-L., and L. Mahrt, 1987: Interaction between soil hydrology and boundary-layer development. Boundary-Layer Meteor., 38, 185-202, doi:10.1007/BF00121563.

Peters-Lidard, C. D., and Coauthors, 2007: High-performance Earth system modeling with NASA/ GSFC's Land Information System. Innovations Syst. Software Eng., 3, 157-165, doi:10.1007/ s11334-007-0028-x.

Prokopy, L. S., and Coauthors, 2013: Agricultural advisors: A receptive audience for weather and climate information? Wea. Climate Soc., 5, 162-167, doi:10.1175/ WCAS-D-12-00036.1.

— - J. S. Carlton, T. Haigh, M. C. Lemos, A. S. Mase, and M. Widhalm, 2017: Useful to usable: Developing usable climate science for agriculture. Climate Risk Manage., 15, 17, doi:10.1016/j.crm.2016.10.004.

Reichle, R. H., R. D. Koster, J. Dong, and A. A. Berg, 2004: Global soil moisture from satellite observations, land surface models, and ground data: Implications for data assimilation. J. Hydrometeor, 5, 430-442, doi:10.1175/1525-7541(2004)005<0430: GSMFSO $>2.0 . \mathrm{CO} ; 2$.

$\longrightarrow,-$ _ G. J. M. De Lannoy, B. A. Forman, Q. Liu, S. P. P. Mahanama, and A. Touré, 2011: Assessment and enhancement of MERRA land surface hydrology estimates. J. Climate, 24, 6322-6338, doi:10.1175/JCLI-D-10-05033.1.

Reynolds, C. A., T. J. Jackson, and W. J. Rawls, 2000: Estimating soil water-holding capacities by linking the Food and Agriculture Organization soil map of the world with global pedon databases and continuous pedotransfer functions. Water Resour. Res., 36, 3653-3662, doi:10.1029/2000WR900130.

Rienecker, M. M., and Coauthors, 2011: MERRA: NASA's Modern-Era Retrospective Analysis for Research and Applications. J. Climate, 24, 3624-3648, doi:10.1175/ JCLI-D-11-00015.1.

Robock, A., C. A. Schlosser, K. Y. Vinnikov, N. A. Speranskaya, J. K. Entin, and S. Qiu, 1998: Evaluation of the AMIP soil moisture simulations. Global Planet. Change, 19, 181-208, doi:10.1016/S0921-8181(98)00047-2.

— , K. Y. Vinnikov, G. Srinivasan, J. K. Entin, S. E. Hollinger, N. A. Speranskaya, S. Liu, and A. Namkhai, 2000: The Global Soil Moisture Data Bank. Bull. Amer. Meteor. Soc., 81, 1281-1299, doi:10.1175/1520-0477(2000)081<1281:TGSMDB > 2.3.CO;2.

Schaefer, G. L., M. H. Cosh, and T. J. Jackson, 2007: The USDA Natural Resources Conservation Service Soil Climate Analysis Network (SCAN). J. Atmos. Oceanic Technol., 24, 2073-2077, doi:10.1175/2007JTECHA930.1.

Schwartz, C. S., and Coauthors, 2009: Next-day convection-allowing WRF Model guidance: A second look at $2-\mathrm{km}$ versus $4-\mathrm{km}$ grid spacing. Mon. Wea. Rev., 137, 3351-3372, doi:10.1175/2009MWR2924.1.

Seneviratne, S. I., T. Corti, E. L. Davin, M. Hirschi, E. B. Jaeger, I. Lehner, B. Orlowsky, and A. J. Teuling, 2010: Investigating soil moisture-climate interactions in a changing climate: A review. Earth-Sci. Rev., 99, 125-161, doi:10.1016/j.earscirev.2010.02.004.

Sinha, T., and K. A. Cherkauer, 2008: Time series analysis of soil freeze and thaw processes in Indiana. J. Hydrometeor, 9, 936-950, doi:10.1175/2008JHM934.1.

Southworth, J., J. C. Randolph, M. Habeck, O. C. Doering, R. A. Pfeifer, D. G. Rao, and J. J. Johnston, 2000: Consequences of future climate change and changing climate variability on maize yields in the midwestern United States. Agric. Ecosyst. Environ., 82, 139-158, doi:10.1016/S0167-8809(00)00223-1.

Taylor, K. E., R. J. Stouffer, and G. A. Meehl, 2012: An overview of CMIP5 and the experiment design. Bull. Amer. Meteor. Soc., 93, 485-498, doi:10.1175/BAMS-D-11-00094.1.

Xia, Y., and Coauthors, 2012: Continental-scale water and energy flux analysis and validation for the North American Land Data Assimilation System project phase 2 (NLDAS-2): 1. Intercomparison and application of model products. J. Geophys. Res., 117, D03109, doi:10.1029/ 2011JD016048. 
Earth Interactions • Volume 21 (2017) • Paper No. 4 • Page 31

— - and Coauthors, 2013: Validation of Noah-simulated soil temperature in the North American Land Data Assimilation System phase 2. J. Appl. Meteor. Climatol., 52, 455-471, doi:10.1175/JAMC-D-12-033.1.

—- M. B. Ek, D. Mocko, C. D. Peters-Lidard, J. Sheffield, J. Dong, and E. F. Wood, 2014a: Uncertainties, correlations, and optimal blends of drought indices from the NLDAS multiple land surface model ensemble. J. Hydrometeor., 15, 1636-1650, doi:10.1175/ JHM-D-13-058.1.

, C. D. Peters-Lidard, D. Mocko, M. Svoboda, J. Sheffield, and E. F. Wood, 2014b: Application of USDM statistics in NLDAS-2: Optimal blended NLDAS drought index over the continental United States. J. Geophys. Res. Atmos., 119, 2947-2965, doi:10.1002/ 2013JD020994.

Earth Interactions is published jointly by the American Meteorological Society, the American Geophysical Union, and the Association of American Geographers. Permission to use figures, tables, and brief excerpts from this journal in scientific and educational works is hereby granted provided that the source is acknowledged. Any use of material in this journal that is determined to be "fair use" under Section 107 or that satisfies the conditions specified in Section 108 of the U.S. Copyright Law (17 USC, as revised by P.IL. 94553) does not require the publishers' permission. For permission for any other from of copying, contact one of the copublishing societies. 